https://doi.org/10.5194/gmd-2020-148

Preprint. Discussion started: 17 July 2020

(c) Author(s) 2020. CC BY 4.0 License.

\title{
1 Surface [Urban] Energy and Water Balance Scheme (v2020a) in non-urban areas: developments, parameters and performance
}

Hamidreza Omidvar', ${ }^{1,}$, Ting Sun 1 , Sue Grimmond ${ }^{1}$, Dave Bilesbach², Andrew Black ${ }^{3}$, Jiquan Chen,

51 Department of Meteorology, University of Reading, Reading, RG6 6BB, UK

62 Biological Systems Engineering Department, University of Nebraska, Lincoln, NE, 68588, USA

$7 \quad{ }^{3}$ Faculty of Land and Food System, University of British Columbia, Vancouver, BC, V6T 1Z4, CA

$8{ }^{4}$ Center for Global Change and Earth Observation, Department of Geography, Michigan State University, East

9 Lansing, MI, 48824, USA

$10{ }^{5}$ Collaborative Innovation Centre on Forecast and Evaluation of Meteorological Disasters, School of Atmospheric

Physics, Nanjing University of Information Science and Technology, Nanjing, 210044, China

${ }^{6}$ State Key Laboratory of Atmospheric Boundary Layer Physics and Atmospheric Chemistry, Institute of Atmospheric

Physics, Chinese Academy of Sciences, Beijing, 100029, China

${ }^{7}$ Department of Environmental Science, Faculty of Science, Shinshu University, Nagano 390-8621, Japan

${ }^{8}$ Department of Geography, University of California, Santa Barbara, CA, 93106 USA

Correspondence to: h.omidvar@reading.ac.uk; c.s.grimmond@reading.ac.uk

ORCID IDs:

Hamidreza Omidvar: https://orcid.org/0000-0001-8124-7264

Ting Sun: $h t t p s: / / o r c i d . o r g / 0000-0002-2486-6146$

Sue Grimmond: https://orcid.org/0000-0002-3166-9415

Dave Bilesbach: https://orcid.org/0000-0001-8661-9178

Andrew Black: $h$ ttps://orcid.org/0000-0001-9292-1146

Jiquan Chen: https://orcid.org/0000-0003-0761-9458

Zexia Duan: https://orcid.org/0000-0003-2822-7066

Zhiqiu Gao: https://orcid.org/0000-0001-8256-005X

Hiroki Iwata: https://orcid.org/0000-0002-8962-8982

Joseph P. McFadden: https://orcid.org/0000-0002-5869-7774 


\section{Abstract}

32 This paper extends the applicability of the SUEWS (Surface [Urban] Energy and Water Balance Scheme)

33 to extensive pervious areas (deciduous trees, evergreen trees, grass, croplands, soil and water) outside

34 cities. It can be used either offline or online (i.e., coupled to weather/climate models). The required

35 parameters to simulate the turbulent latent heat (or evaporative) flux are derived using observations. Both

36 the parameters (leaf area index (LAl), albedo, roughness parameters and surface conductance) and the

37 surface energy balance fluxes are evaluated at independent sites and/or different periods at the same

38 site. Methods to obtain parameters and guidance to apply SUEWS are provided. Results demonstrate the

39 impacts from differences in LAI dynamics and albedo for various types of vegetation. The relation

40 between LAI and albedo is explored. Deciduous, evergreen, and grass land covers all have long periods

41 of LAl maxima, but croplands normally have a short sharp peak due to harvesting. For most of the

42 vegetation types studied the maximum albedo coincides with the maximum LAl period, but for some

43 evergreen trees the maxima are associated with leaves changing colour (needles/leaves get darker as

44 they age during autumn and winter). Ensuring these dynamics are captured is important for assessing

45 urban-rural differences (e.g. canopy layer air temperature).

46 Keywords: SUEWS, pervious land cover, leaf area index, albedo, evaporation flux, roughness parameters

\section{Introduction}

48 Key to advancing our knowledge of planetary boundary layer behaviour is understanding

49 surface-atmosphere interactions. Various land surface models (LSM) simulate these energy and

50 water exchanges (Ek et al., 2003; Levis et al., 2004; Krinner et al., 2005; Kowalczyk et al.,

51 2006). 'Urban' land use is amongst the most diverse (e.g. high-rise central business district to

52 one-storey single family residential areas) with many land-cover types (e.g. paved roads,

53 buildings, parks with trees and grass) influencing energy and water surface-atmosphere

54 exchange through a wide range of complex biophysical processes. The complexity of urban

55 systems have grown substantially with urbanization (United Nations 2018). A number of LSMs

56 have been designed for urban areas (Grimmond et al., 2010), to capture processes such as

57 heat and water released by anthropogenic activities (Grimmond et al., 1986; Grimmond, 1992;

58 Masson, 2000; Kusaka et al., 2001; Martilli et al., 2002).

59 The Surface [Urban] Energy and Water Balance Scheme (SUEWS, Grimmond et al., 1986,

60 1991, Grimmond \& Oke 1991, Järvi et al., 2011) characterises the heterogeneity of urban

61 surfaces using seven land covers split between impervious (buildings, paved) and pervious 
62 (evergreen trees/shrubs, deciduous trees/shrubs, grass, soil, water) types. SUEWS has been 63 evaluated in multiple cities globally (e.g. Karsisto et al., 2016, Ward et al., 2016, Ao et al., 64 2018, Kokkonen et al., 2018, Harshan et al., 2018) with varying mixes of integrated imperviouspervious land covers. However, when extensive areas of one type of pervious land cover (e.g. deciduous trees) occurs (e.g. in rural areas) some parameters are expected to differ from integrated-urban values (i.e. obtained for built-up areas). Most notably, there will be differences in parameters that are associated with the surface resistances for latent heat flux calculations because of differences in sub-grid-scale advection processes (Spronken-Smith et al., 2000). Thus, new parameters need to be determined from observations.

Our objective is to bridge this gap by deriving values for several latent heat flux related parameters (viz, leaf area index (LAl), albedo, roughness parameters and surface resistance) for extensive non-urban pervious areas and assess their seasonal variability. This improves SUEWS regional applicability with rural areas with forests, farms, and grasslands (etc.). For reproducibility and applicability to other data sets parameter derivation is implemented in Python Jupyter notebooks (Omidvar et al., 2020). The SUEWS model (Sect. 2.1, Appendix A) is used with observations (Sect. 2.2) from numerous sites. Methods address both obtaining the parameters and their evaluation (Sect. 2.3). The derived parameters (Sect. 3) are evaluated (Sect. 4), allowing conclusions to be drawn (Sect. 5).

\section{Methods}

\subsection{SUEWS and its vegetation-related sub-models}

The details of how SUEWS computes the surface energy, water and carbon fluxes are given in Järvi et al. (2011), Ward et al. (2016), and Järvi et al. (2019). The surface energy and water balances are directly linked by the turbulent latent heat flux $\left(Q_{E}\right)$ or its mass equivalent evaporation $(E)$ :

$$
\begin{gathered}
Q^{*}+Q_{F}=Q_{H}+Q_{E}+\Delta Q_{S} \\
P+I_{e}=E+R+\Delta S
\end{gathered}
$$

where $Q^{*}$ is the net all-wave radiation flux, $Q_{F}$ is the anthropogenic heat flux, $Q_{H}$ is the turbulent sensible heat flux, $\Delta Q_{S}$ the net storage heat flux, and $P, I_{e}, \Delta S$ and $R$ are precipitation, external water use, net change in the canopy water storage and runoff, respectively. As we focus on extensive (non-urban) pervious areas the anthropogenic heat flux $\left(Q_{F}\right)$ is assumed to be $0 \mathrm{~W}$ $\mathrm{m}^{-2}$. 
Vegetation phenology changes key model parameters, most notably, leaf area index (LAI). Leafout and senescence impact the albedo $(\alpha)$ and therefore surface radiative exchanges. LAI changes also modify both aerodynamic roughness parameters (roughness length $\left(z_{0}\right)$, zero plane displacement height $\left.\left(z_{d}\right)\right)$ (e.g. Kent et al., 2017) and surface resistance $\left(r_{s}\right)$. The former impacts aerodynamic resistance $\left(r_{a}\right)$ while $r_{s}$ directly moderates $Q_{E}$ (Sect. 2.1.4).

Model parameters need to be internally consistent for land cover type $i$. This allows different types of vegetation (e.g. a crop) to be simulated. All the parameters needed for a vegetated surface and those addressed in this paper are given in Table 1. SUEWS allows parameters to vary between individual grids (Järvi et al., 2019, Sun et al., 2020) and thus can represent a high degree of spatial heterogeneity (e.g. different heights of trees).

Table 1: Parameters that SUEWS uses (and can be set) for pervious surface types by first associated process (i.e. most impact multiple variables). Those determined (D) in this study $\left({ }^{*}\right)$ and the values used (given in Table: T\#, Sect.: S\#) in individual equations (E).

\begin{tabular}{|c|c|c|c|c|c|}
\hline Category & Symbol & Definition & Value & $\mathbf{E}$ & D \\
\hline \multirow{3}{*}{ Radiation } & $\alpha_{L A I_{\min }}$ & Albedo at $L A I_{\min }$ & T4 & 6 & \\
\hline & $\alpha_{L A I_{\max }}$ & Albedo at $L A I_{\max }$ & T4 & 6 & \\
\hline & $\varepsilon_{0}$ & Emissivity & T2 & & \\
\hline \multirow{6}{*}{$\begin{array}{l}\text { Leaf Area Index } \\
\qquad(L A I)\end{array}$} & $L A I_{\min }$ & LAI Minimum & T4 & 4,5 & \\
\hline & $L A I_{\max }$ & LAI Maximum & T4 & 4.5 & \\
\hline & $T_{\text {BaseSDD }}$ & $\begin{array}{l}\text { Base temperature senescence degree days } \\
(S D D)\end{array}$ & T4 & 4 & \\
\hline & $T_{\text {BaseGDD }}$ & Base temperature for growing degree days & T4 & 4 & \\
\hline & $G D D_{v}$ & GDD from the start of the crop vegetative phase & T4 & 5 & \\
\hline & $G D D_{L A I_{m}}$ & Growing degree days until $L A I_{\max }$ & T4 & 5 & * \\
\hline \multirow{3}{*}{ Roughness } & $H_{v}$ & Vegetation height & T3 & & \\
\hline & $z_{0 m}$ & Roughness length for momentum & S2.1.4 & 9 & \\
\hline & $z_{d}$ & Zero plane displacement & S2.1.4 & 9 & \\
\hline \multirow{5}{*}{$\begin{array}{l}\text { Surface } \\
\text { resistance }\end{array}$} & G2-G6 & Coefficients & T5 & 12 & \\
\hline & $G_{\max }$ & Coefficients & T5 & 12 & \\
\hline & $T_{H}, T_{L}$ & Temperature limits for switching off evaporation & S2.1.4 & 15 & \\
\hline & $s_{1}$ & Coefficient related to wilting point & S2.1.4 & 16 & \\
\hline & $K_{\downarrow, \max }$ & Maximum observed incoming shortwave & S2.1.4 & 13 & \\
\hline Storage heat flux & $a_{1}-a_{3}$ & Coefficient for storage heat flux & T2 & 7 & \\
\hline Water storage & $S_{i}$ & Canopy water storage capacity & T2 & 19 & \\
\hline
\end{tabular}

\subsubsection{Leaf Area Index (LAI)}

In SUEWS, LAI for the current day $(d)$ is calculated using cumulative growing degree days

$108(G D D)$ and senescence degree days $(S D D)$ of the previous day $(d-1)$ for vegetation type $i$. For 109 forests and grass we use (Järvi et al., 2011): 


$$
L A I_{d, i}= \begin{cases}\min \left(L A I_{\mathrm{max}, \mathrm{i}}, L A I_{d-1, i}^{\omega_{1}} G D D \omega_{2}+L A I_{d-1, i}\right), & T_{\text {BasesDD }}<T_{d}<T_{\text {BaseGDD }} \\ \max \left(L A I_{\mathrm{min}, \mathrm{i}}, L A I_{d-1, i}^{\omega_{1}} S D D \omega_{2}+L A I_{d-1, i}\right), & T_{\text {BaseGDD }}<T_{d}<T_{\text {BasesDD }}\end{cases}
$$

111 with $\omega_{1}=30 \times 10^{-3}$ and $\omega_{2}=0.5 \times 10^{-3}$. The base temperatures associated with the initiation

112 of leaf-on ( $\left.T_{\text {BaseGDD }}\right)$ and leaf-off $\left(T_{\text {BaseSDD }}\right.$, units $\left.{ }^{\circ} \mathrm{C}\right)$ periods are used relative to a mean air

113 temperature $T_{d}$ derived from the daily maximum $\left(T_{a}^{\max }\right)$ and minimum $\left(T_{a}^{\min }\right)$ for the current day:

$$
T_{d}=\frac{T_{a}^{\max }+T_{a}^{\min }}{2}
$$

115 The model requires the maximum and minimum $L A /$ values $\left(L A I_{\max , i}, L A I_{\min , i}\right)$ for each

116 vegetation type. Eq. 3 has fewer calibration parameters than Eq. A1 of Järvi et al. (2014) as

$117 T_{B a s e G D D}$ and $T_{B a s e S D D}$ are determined for each site (Sect. 2.3). If $T_{B a s e G D D}$ and $T_{B a s e S D D}$ are

118 available for a site, one should account for day-length and photoperiod for more northerly sites

119 (Bauerle et al., 2012; Gill et al., 2015).

120 For crops (e.g. rice, wheat) $L A l$ also depends on the planting date. However, as crops are 121 grown to be harvested, the period of $L A I_{\max }$ is short (cf. e.g. forests as parametrised in Eq. 3).

122 We propose:

$L A I_{d, \text { crop }}=\left\{\begin{array}{l}\min \left(L A I_{\max } \frac{L A I_{\text {max }}-L A I_{\text {min }}}{G D D_{L A I_{\max }}-G D D_{v}}\left(G D D_{p}-G D D_{v}\right)+L A I_{\min }\right) G D D_{p} \leq G D D_{L A I_{\max }} \\ \max \left(L A I_{\min },-\frac{L A I_{\max }-L A I_{\min }}{G D D_{L A I_{\max }}-G D D_{v}}\left(G D D_{p}-G D D_{v}\right)+2 L A I_{\max }-L A I_{\min }\right) G D D_{p}>G D D_{L A I_{\max }}\end{array}\right.$

where $G D D_{p}$ is the $G D D$ accumulated from the day of planting; $G D D_{L A I_{\max }}$ is associated with $L A I_{\max }$ and $G D D_{v}$ is the start of crop vegetative phase. Note that $G D D, S D D$, and $G D D_{p}$ (in Eq. 4 and 5) change with time from their base temperatures ( $T_{\text {BaseGDD }}$ for $G D D, T_{B a s e S D D}$ for $S D D, 0{ }^{\circ} \mathrm{C}$ for $G D D_{d}$ ). Using a different base temperature (than $0^{\circ} \mathrm{C}$ ) to calculate $G D D_{d}, G D D_{v}$, and $G D D_{L A I_{\max }}$ in Eq. 5 leads to same $L A I_{d, c r o p}$ results as only the difference values $G D D_{L A I_{\text {max }}}-$ $G D D_{v}$ and $G D D_{p}-G D D_{v}$ are important. Here, these crop specific coefficients are obtained for rice and winter wheat (Sect. 2.3).

\subsubsection{Albedo $(\alpha)$}

In SUEWS, the albedo varies with daily $L A I$ between the minimum $\left(\alpha_{L A I_{\min }}\right)$ and maximum $\left(\alpha_{L A I_{\max }}\right)$ by vegetation type:

$$
\alpha_{d, i}=\alpha_{d-1, i}+\left(\alpha_{L A I_{\max , i}}-\alpha_{L A I_{\min , i} i}\right) \frac{L A I_{d, i}-L A I_{d-1, i}}{L A I_{\max , i}-L A I_{\min , i}}
$$


135 The maximum albedo does not necessarily occur with the maximum $L A I$ because of change in 136 leaf/needle colour (Sect. 3.1). Here we focus on snow-free conditions, albeit a snow module is

137 available in SUEWS (Järvi et al., 2014). Bare soil and water albedo are assumed to be constant 138 in a model run (Sect. 3.2).

139 The observed (30 $\mathrm{min}$ ) incoming and outgoing shortwave radiation are used to calculate each 140 albedo from 10:00 to 14:00 (local standard time). From this, one mean albedo for each day is 141 calculated. The two model parameters (Eq. 6, Table 1) are selected from those that minimize 142 the mean absolute error (MAE, Sect. 2.4) of the albedo prediction at a calibration site.

143 Within SUEWS the albedo is used with the observed incoming shortwave radiation to obtain $Q^{*}$. 144 In the current analyses, the observed incoming longwave $\left(L_{\downarrow}\right)$ and modelled outgoing longwave 145 radiation $\left(L_{\uparrow}=\left(1-\varepsilon_{0}\right) L_{\downarrow}+\varepsilon_{0} \sigma T_{s}^{4}\right.$ where $\varepsilon_{0}$ is the surface emissivity, $\sigma$ is the Stefan Boltzmann 146 constant $\left(\mathrm{W} \mathrm{m}^{-2} \mathrm{~K}^{-4}\right)$, and $T_{s}$ is the surface temperature $(\mathrm{K})$, Appendix A.1) are used. Table 2 147 gives the emissivity values used.

148 To determine $\alpha_{L A I_{\min }}$ and $\alpha_{L A I_{\max }}$ for each individual vegetated site (excluding snow) we analyse 149 observational data for snow free periods. Although SUEWS has a snow option, this option is 150 disabled in all runs to verify "no snow" scenarios. We assume precipitation is snow if $T_{a}<0{ }^{\circ} \mathrm{C}$ 151 (Järvi et al., 2014), and that snow remains until the 5-day moving average of air temperature is above $5^{\circ} \mathrm{C}$. Although this method will not flag all the snow-covered days (e.g. duration of snow 153 cover also depends on snow depth), it provides a rough estimate of when the albedo is affected 154 by snow.

Table 2: Pervious surface OHM storage heat flux $\left(a_{1}, a_{2}, a_{3}\right)$ coefficients are derived (this study O20, methods: Sect. 2.1.3), except for tree and grass areas which are derived from literature sources (D85= Doll et al. (1985), M85= McCaughey (1985)) by Grimmond et al. (1991) and Grimmond and Oke (1999)); canopy water storage $\left(S_{i}, E q\right.$. 19) from B03= Breuer et al. (2003), and emissivity from sources in W16 - Ward et al. (2016).

\begin{tabular}{|c|c|c|c|c|c|c|c|c|}
\hline Vegetation Type & $\boldsymbol{a}_{\mathbf{1}}$ & $\boldsymbol{a}_{\mathbf{2}}$ & $\boldsymbol{a}_{\mathbf{3}}$ & Source & $\begin{array}{c}\boldsymbol{S}_{\boldsymbol{i}} \\
(\mathbf{m m})\end{array}$ & Source & Emissivity & $\begin{array}{c}\text { Sources } \\
\text { in }\end{array}$ \\
\hline Deciduous trees/shrubs & 0.215 & 0.325 & -19.9 & $\mathrm{M} 85$ & 1.3 & $\mathrm{~B} 03$ & 0.98 & $\mathrm{~W} 16$ \\
\hline Evergreen trees/shrubs & 0.215 & 0.325 & -19.9 & $\mathrm{M} 85$ & 0.8 & $\mathrm{~B} 03$ & 0.98 & $\mathrm{~W} 16$ \\
\hline Grass & 0.215 & 0.325 & -19.9 & $\mathrm{D} 85$ & 1.9 & $\mathrm{~B} 03$ & 0.93 & $\mathrm{~W} 16$ \\
\hline Rice & 0.185 & 0.615 & -18.0 & $\mathrm{O} 20$ & 1.9 & $\mathrm{~B} 03$ & 0.95 & Water \\
\hline Wheat & 0.283 & 0.784 & -18.0 & $\mathrm{O} 20$ & 1.9 & $\mathrm{~B} 03$ & 0.93 & Grass \\
\hline Soil & 0.210 & 0.902 & -20.4 & $\mathrm{O} 20$ & 1.9 & $\mathrm{~B} 03$ & 0.93 & $\mathrm{~W} 16$ \\
\hline Water & 0.880 & 0.370 & -85.4 & $\mathrm{O} 20$ & - & - & 0.95 & $\mathrm{~W} 16$ \\
\hline
\end{tabular}




\subsubsection{Storage heat flux $\left(\Delta Q_{s}\right)$}

161 Storage heat flux is simulated with the objective hysteresis model (OHM, Grimmond et al., 1991):

$$
\Delta Q_{S}=\sum_{i} f_{i}\left[a_{1, i} Q^{*}+a_{2, i} \frac{\partial Q^{*}}{\partial t}+a_{3, i}\right]
$$

where $f_{i}$ is the plan area (or 3d, Grimmond et al. 1991, Grimmond and Oke 1999) fraction of surface $i$ and $a_{1-3}$ are the OHM coefficients (Table 2). To obtain $a_{1-3}$ from observations of $Q^{*}$ and $\Delta Q_{S}$ (as the residual of Eq. 1 , in extensive pervious sites $Q_{F}=0 \mathrm{~W} \mathrm{~m}^{-2}$ ) regression is used. As the sites are assumed to be extensively the same pervious land cover type $f_{i}=1$ in each case. We determine one set of OHM coefficients per site, hence assuming they are constant and ignoring soil wetness effects and other variations.

\subsubsection{Latent heat flux $\left(Q_{E}\right)$}

In SUEWS, a modified Penman-Monteith equation (Penman, 1948; Monteith, 1965) is used to compute $Q_{E}$ with $Q_{F}=0 \mathrm{~W} \mathrm{~m}^{-2}$ in non-urban areas (e.g. this paper) and greater than zero for cities (Grimmond \& Oke 1991):

$$
Q_{E}=\frac{s\left(Q^{*}+Q_{F}-\Delta Q_{S}\right)+\frac{\rho c_{p} V}{r_{a}}}{s+\gamma\left(1+\frac{r_{s}}{r_{a}}\right)}
$$

The atmospheric state is obtained from the slope of saturation vapour pressure curve with respect to temperature $\left(s\right.$, units: $\left.\mathrm{Pa} \mathrm{K}^{-1}\right)$, density of air $\left(\rho, \mathrm{kg} \mathrm{m}^{-3}\right)$, specific heat of air at constant pressure $\left(c_{p}, \mathrm{~J} \mathrm{~K}^{-1} \mathrm{~kg}^{-1}\right)$, vapour pressure deficit $(V, \mathrm{~Pa})$, psychrometric 'constant' $\left(\gamma,: \mathrm{Pa} \mathrm{K}{ }^{-1}\right)$, and the aerodynamic resistance for water vapour $\left(r_{a}\right.$, units: $\left.\mathrm{s} \mathrm{m}^{-1}\right)$. The latter is obtained from Ulden \& Holtslag (1985) and Järvi et al. (2011):

$$
r_{a}=\frac{\left[\ln \left(\frac{z_{m}-z_{d}}{z_{0 m}}-\psi_{m}(\zeta)\right)\right]\left[\ln \left(\frac{z_{m}-z_{d}}{z_{0 v}}-\psi_{v}(\zeta)\right)\right]}{\kappa^{2} u},
$$

where $z_{m}$ is the measurement height for mean wind speed $(u)$ and $\kappa$ the von Kármán constant (0.4 assumed); the aerodynamic parameters $z_{d}$ (zero plane displacement height) and $z_{0 m}$ (roughness length for the momentum) are estimated as a function of canopy height which varies for different $L A$ / states of each surface, as discussed in Appendix B (Garratt, 1994; Grimmond and Oke, 1999). For water and soil surfaces they are estimated to be $z_{o m}=0.0005 \mathrm{~m}$ and 0.002 $\mathrm{m}$ respectively with $z_{d}=0 \mathrm{~m}$ (Moene and van Dam, 2013). Canopy height for the different surface types is given in Table 3 . The stability scale $\zeta\left(=\left(z_{m}-z_{d}\right) / L\right)$ depends on $L$ the 
roughness length for vapour $\left(z_{o v}\right)$ is calculated as $z_{o v}=0.1 z_{o m}$ (Brutsaert, 1982) and assumed to be the same as for sensible heat. The atmospheric stability functions of momentum $\left(\psi_{m}\right)$ and water vapour $\left(\psi_{v}\right)$ for unstable condition are (Campbell and Norman, 1998):

$$
\psi_{v}=2 \ln \left[\frac{1+(1-16 \zeta)^{1 / 2}}{2}\right],
$$

and for stable condition (Campbell and Norman, 1998; Högström, 1988):

$$
\begin{aligned}
& \psi_{v}=-4.5 \ln (1+\zeta) \\
& \psi_{m}=-6 \ln (1+\zeta)
\end{aligned}
$$

For completely wet surfaces, the surface resistance $\left(r_{s}\right)$ is assumed to be $0 \mathrm{~s} \mathrm{~m}^{-1}$ (i.e. potential evaporation is calculated from Eq. 8). Otherwise $r_{s}$, or its inverse surface conductance $\left(g_{s}\right)$, is modelled (Ward et al., 2016):

$$
r_{s}^{-1}=g_{s}=\sum_{i}\left(g_{\text {max }, i} f_{i}\right) g\left(L A I_{i}\right) g\left(K_{\downarrow}\right) g(\Delta q) g\left(T_{a}\right) g\left(\Delta \theta_{\text {soil }}\right) .
$$

To reduce the number of coefficients in Ward et al.'s (2016), $G_{1}$ (their Eq. 9) is removed from the first term (of Eq. 12) leaving $g_{\text {max }, i}$ (maximum surface conductance, units: $\mathrm{m} \mathrm{s}^{-1}$ ) and $f_{i}$. For 'homogeneous' sites (Sect. 2.2) $f_{i}=1$. Phenological state is critical: $g\left(L A I_{i}\right)=\frac{L A I_{i}}{L A I_{\max , i}}$. For bare soil surfaces (i.e. no vegetation), when $L A l$ is irrelevant $g\left(L A I_{i}\right)=1$. The remaining terms are related to meteorology (incoming shortwave radiation $K_{\downarrow}$, specific humidity deficit $\Delta q$, air temperature $T_{a}$ ), and soil moisture deficit ( $\Delta \theta_{\text {soil }}$, difference between soil moisture and soil water capacity); using Grimmond \& Oke (1991), Järvi et al. (2011), and Ward et al. (2016):

$$
g\left(K_{\downarrow}\right)=\frac{\frac{K_{\downarrow}}{G_{2}+K_{\downarrow}}}{\frac{K_{\downarrow, \text { max }}}{G 2+K_{\downarrow, \text { max }}}}
$$

207

208

209

210

211

212

213

where $K_{\downarrow, \max }$ is the maximum observed incoming shortwave radiation $\left(=1200 \mathrm{~W} \mathrm{~m}^{-2}\right)$;

$$
\begin{gathered}
g(\Delta q)=G_{3}+\left(1-G_{3}\right) G_{4}^{\Delta q} \\
g\left(T_{\text {air }}\right)=\frac{\left(T_{a i r}-T_{L}\right)\left(T_{H}-T_{a}\right)^{T_{c}}}{\left(G_{5}-T_{L}\right)\left(T_{H}-G_{5}\right)^{T_{c}}}
\end{gathered}
$$

where $T_{C}=\frac{T_{H}-G_{5}}{G_{5}-T_{L}}$ is a function of the lower $\left(T_{L}=-20^{\circ} \mathrm{C}\right)$ and upper $\left(T_{H}=55^{\circ} \mathrm{C}\right)$ limits that determine when the evaporation switches off in SUEWS. Here we extended $T_{L}$ from $-10^{\circ} \mathrm{C}$ (from Ward et al., 2016) to $-20^{\circ} \mathrm{C}$ to ensure that the temperature limit covers all climates (Table 3) studied here. Note $Q_{E}$ is negligible (Appendix C) when $T_{a}<-20^{\circ} \mathrm{C}$. 
214 The soil moisture control considers the wilting point $\left(\Delta \theta_{W P}=\frac{s_{1}}{G_{6}}\right.$, with $s_{1}=5.56$, see Järvi et al.

215 2011) using $G_{6}$ to vary with soil and plant type:

$$
g\left(\Delta \theta_{\text {soil }}\right)=\frac{1-\exp \left(G_{6}\left(\Delta \theta_{\text {soil }}-\Delta \theta_{W P}\right)\right)}{1-\exp \left(-G_{6} \Delta \theta_{W P}\right)}
$$

217 To obtain the $G_{2}$ to $G_{6}$ and $g_{\text {max }}$, a so-called 'observed' $g_{s}$ is obtained by rearranging Eq. 8,

218 when the surface is dry (and both $Q_{H}$ and $Q_{E}$ are $>0 \mathrm{~W} \mathrm{~m}^{-2}$ ):

$$
\frac{1}{g_{s}}=r_{s}=\left[\frac{s}{\gamma} \frac{Q_{H}}{Q_{E}}-1\right] r_{a}+\frac{\rho c_{p} V}{\gamma Q_{E}} .
$$

220

221

222

223

224

225

226

The $g_{s}$ related parameters (Eq. 12) are obtained using non-linear regression with the observed values (Eq. 17). We use a Python package Platypus (Hadka, 2015) with a multi-objective evolutionary algorithm (Zhou et al., 2011) so that we capture: (1) variations of $g_{s}$ : difference between standard deviation of $g_{s}$ from model and observations (normalized by standard deviation of observations); and (2) magnitude of $g_{s}$ : mean absolute difference between $g_{s}$ from model and observations.

SUEWS has a running water balance that accounts for the multiple surface types. The amount of water on the canopy of each surface $\left(C_{i}\right)$ (Grimmond \& Oke 1991) is used to vary the surface resistance between dry and wet $\left(r_{s}=0 \mathrm{~s} \mathrm{~m}^{-1}\right)$ by replacing $r_{s}$ with $r_{s s}$ (Shuttleworth 1978):

$$
r_{\mathrm{ss}}=\left[\frac{W}{r_{b}(s / \gamma+1)}+\frac{(1-W)}{r_{s}+r_{b}(s / \gamma+1)}\right]^{-1}-r_{b}(s / \gamma+1),
$$

where $W$ is a function of the relative amount of water present on each surface to its water storage capacity $\left(S_{i}\right.$, Table 2$)$ :

$$
\begin{array}{cc}
W=1 & C_{i} \geq S_{i} \\
W=\frac{K-1}{K-S_{i} / C_{i}} & C_{i}<S_{i}
\end{array}
$$

$K$ depends on the aerodynamic and surface resistances:

$$
K=\frac{\left(r_{s} / r_{a}\right) /\left(r_{a}-r_{b}\right)}{r_{s}+r_{b}(s / \gamma+1)}
$$

where $r_{b}$, the boundary layer resistance, is a function of friction velocity $u_{*}$ (Shuttleworth 1983):

$$
r_{b}=1.1 u_{*}^{-1}+5.6 u_{*}^{\frac{1}{3}} .
$$

Equations 18-21 ensure that the surface resistance $r_{S S}$ has a smooth transition from 0 (a completely wet surface) to $r_{s}$ (a dry surface). 


\subsection{Observations and sites}

To determine parameters for non-urban surfaces (Table 1), and to evaluate their performance, observations from "homogeneous" sites with long term radiation fluxes and eddy covariance measurements are required (Table 3). The $30 \mathrm{~min}$ meteorological observations used are air temperature, incoming shortwave radiation, upwelling shortwave radiation, station pressure, relative humidity, wind speed, precipitation, net all-wave radiation, sensible heat flux and evaporation flux. The precipitation data are used to select dry periods and are required by SUEWS to calculate $\Delta \theta_{\text {soil }}$ and the surface state $\left(C_{i}\right)$.

The site land cover characteristics are provided by their key references (Table 3). The observed LAI data are from the NASA Moderate Resolution Imaging Spectroradiometer (MODIS, Nishihama et al., 1997) four-day composite product MCD15A3H (Myneni et al., 2015) with 500 $\mathrm{m}$ resolution.

The sites (Fig. 1) in North America are part of the AmeriFlux network (Baldocchi et al., 2001) and two of the Asian sites are part of AsiaFlux (AsiaFlux, data access: 2020-01-22). Seven land cover types are analysed (Table 3 ) using one to three sites:

(1) Deciduous trees (DBF): three sites

(2) Evergreen trees (ENF): three sites

(3) Grass (GRA): two sites

(4) Rice (RIC): two sites

(5) Winter wheat (WHT): one site

(6) Water (WAT): one continuous and two intermittent flood irrigated rice sites (Table 3)

(7) Bare soil (BSV): two sites (up to four weeks after rice planting).

Irrigation ( $I_{e}$, Eq. 2) modifies both the soil moisture deficit and surface state and is critical for the growth of many plants. Notably rice has flood irrigation for a period when a site-specific depth (Table 3) is maintained. At CN-DNT (Table 3) this occurs until 5 weeks before harvest, whereas at PH-IRI there are only 2 weeks without irrigation. The CN-DNT wheat field is kept saturated but not flooded for the entire time (Duan et al., 2020). To account for this, sufficient water is added by SUEWS to satisfy these conditions (Appendix A.2 gives details).

Table 3: Analysed pervious land cover types (DBF: Deciduous Broadleaf Forests, ENF: Evergreen Needleleaf Forests, GRA: Grasslands, CRP: crops, BSV: bare soil, WAT: Water) at different sites and periods. Key references and $D O I$ provide the details of the observations and each site. The sites elevation (elev) above sea level (asl), vegetation height $\left(H_{v}\right)$ above ground level (agl) and height of 
https://doi.org/10.5194/gmd-2020-148

Preprint. Discussion started: 17 July 2020

(c) Author(s) 2020. CC BY 4.0 License. and USA (US). At CN-DNT both rice (RIC) and wheat (WHT) are grown.

\begin{tabular}{|c|c|c|c|c|c|c|c|c|c|c|c|c|}
\hline Site & Name & Type & $\begin{array}{l}\text { Mean } \\
\text { Temp. } \\
\left({ }^{\circ} \mathrm{C}\right)^{1}\end{array}$ & $\begin{array}{c}\text { Elev. } \\
\text { (m asl) }\end{array}$ & $\begin{array}{c}H_{v} \\
(\mathrm{~m} \text { agl })\end{array}$ & $\begin{array}{c}H_{u} \\
(\mathrm{~m} \text { agl })\end{array}$ & $\begin{array}{l}\text { Lat. } \\
\left({ }^{\circ} \mathrm{N}\right)\end{array}$ & $\begin{array}{l}\text { Lon. } \\
\left({ }^{\circ}\right)\end{array}$ & $\begin{array}{c}\text { Calibration } \\
\text { year }\end{array}$ & Test years & DOI & Key Reference \\
\hline US-MMS & $\begin{array}{c}\text { Morgan Monroe State } \\
\text { Forest }\end{array}$ & DBF & $\mid$\begin{tabular}{|l|}
13.2 \\
\end{tabular} & 275.0 & 25.0 & 46.0 & 39.32 & -86.41 & 2017 & \begin{tabular}{|c|}
2010,2012 \\
2016 \\
\end{tabular} & 10.17190/AMF/1246080 & Schmid et al. (2000) \\
\hline US-UMB & $\begin{array}{c}\text { Univ. Michigan } \\
\text { Biological Station }\end{array}$ & DBF & 7.1 & 234.0 & 20.0 & 46.0 & 45.56 & -84.71 & 2008 & \begin{tabular}{|c|}
2010,2014 \\
2016
\end{tabular} & 10.17190/AMF/1246107 & Curtis et al. (2002) \\
\hline US-Oho & Oak Openings & DBF & 11.0 & 230.0 & 24.0 & 34.0 & 41.55 & -83.84 & 2010 & $\begin{array}{c}2011,2012 \\
2013\end{array}$ & 10.17190/AMF/1246089 & Noormets et al. (2008) \\
\hline CA-Obs & \begin{tabular}{|c|} 
Saskatchewan - \\
Western Boreal, \\
Mature Black Spruce
\end{tabular} & ENF & 1.3 & 628.9 & 7.2 & 26.0 & 53.99 & -105.12 & 2008 & $\begin{array}{c}2003,2005 \\
2006\end{array}$ & 10.17190/AMF/1375198 & Bergeron et al. (2007) \\
\hline CA-Qcu & \begin{tabular}{|c|} 
Quebec - Eastern \\
Boreal, Black Spruce \\
/Jack Pine Cutover
\end{tabular} & ENF & 1.6 & 392.3 & 13.8 & 24.0 & 49.27 & -74.04 & 2010 & $\begin{array}{c}2005,2008 \\
2009\end{array}$ & 10.17190/AMF/1246828 & Bergeron et al. (2007) \\
\hline US-Blk & Black Hills & ENF & 6.6 & 1718.0 & $13.0^{2}$ & 24.0 & 44.16 & -103.65 & 2005 & \begin{tabular}{|c|}
2004,2006 \\
2008 \\
\end{tabular} & 10.17190/AMF/1246031 & - \\
\hline US-KUT & KUOM Turfgrass Field & GRA & 8.0 & 301.0 & 0.07 & 1.35 & 44.99 & -93.19 & 2008 & 2006,2007 & 10.17190/AMF/1246145 & Peters et al. (2011) \\
\hline US-AR1 & $\begin{array}{c}\text { ARM USDA UNL OSU } \\
\text { Woodward } \\
\text { Switchgrass } 1\end{array}$ & GRA & 15.6 & 611.0 & $1.0^{3}$ & 2.84 & 36.43 & -99.42 & 2012 & 2010,2011 & 10.17190/AMF/1246137 & - \\
\hline CN-DNT & $\begin{array}{l}\text { Rice-wheat rotation } \\
\text { cropland Dongtai } \\
\text { country, Jiangsu }\end{array}$ & $\begin{array}{l}\mathrm{CRP} \\
\mathrm{BSV}^{4}\end{array}$ & 15.1 & 4.0 & $\begin{array}{l}0.6(\mathrm{R}) \\
0.5(\mathrm{~W})\end{array}$ & 10.0 & 32.76 & 120.47 & $\begin{array}{c}2015(R)^{5} \\
2015-16(W)^{6}\end{array}$ & \begin{tabular}{|c|}
$2016(\mathrm{R})$ \\
$2014-15(\mathrm{~W})$
\end{tabular} & - & Duan et al. (2020) \\
\hline JP-SWL & $\begin{array}{c}\text { Suwa Lake site } \\
\text { Suwa city, Nagano }\end{array}$ & WAT & 14.6 & 759.0 & & 3.0 & 36.04 & 138.10 & April 2015 & $\begin{array}{c}\text { May-Dec } \\
2015\end{array}$ & www.asiaflux.net & Iwata et al. (2018) \\
\hline $\mathrm{PH}-\mathrm{IRI}$ & Los Banos, Laguna & $\begin{array}{l}\text { CRP, } \\
\mathrm{BSV}^{4} \\
\end{array}$ & 27.5 & 21.0 & 1.0 & 2.25 & 14.2 & 121.3 & $2014^{7}$ & 2013 & www.asiaflux.net & Alberto et al. (2009) \\
\hline
\end{tabular}

273 1 For years used in this study

274 2 Source: Keyser et al. (2008)

$276 \quad 4$ First 4 weeks after planting rice - considered as soil surface.

2775 Rice planted and harvested: Jun 20-Nov 7 in 2015 and Jun 16-Nov 5 in 2016 . Field flooded $(0.15 \mathrm{~m})$ until 5 weeks prior to harvest.

2786 Wheat planted and harvested: Dec 15-May 31 in 2014-15 and Dec 10-May 25 in 2015-16. Field kept saturated the entire period.

2797 Rice planted and harvested: Jun 27-October 22 in 2013 and Jun 17-Oct 1 in 2014. Field flooded (0.3 m) until 2 weeks prior to

280 harvest.
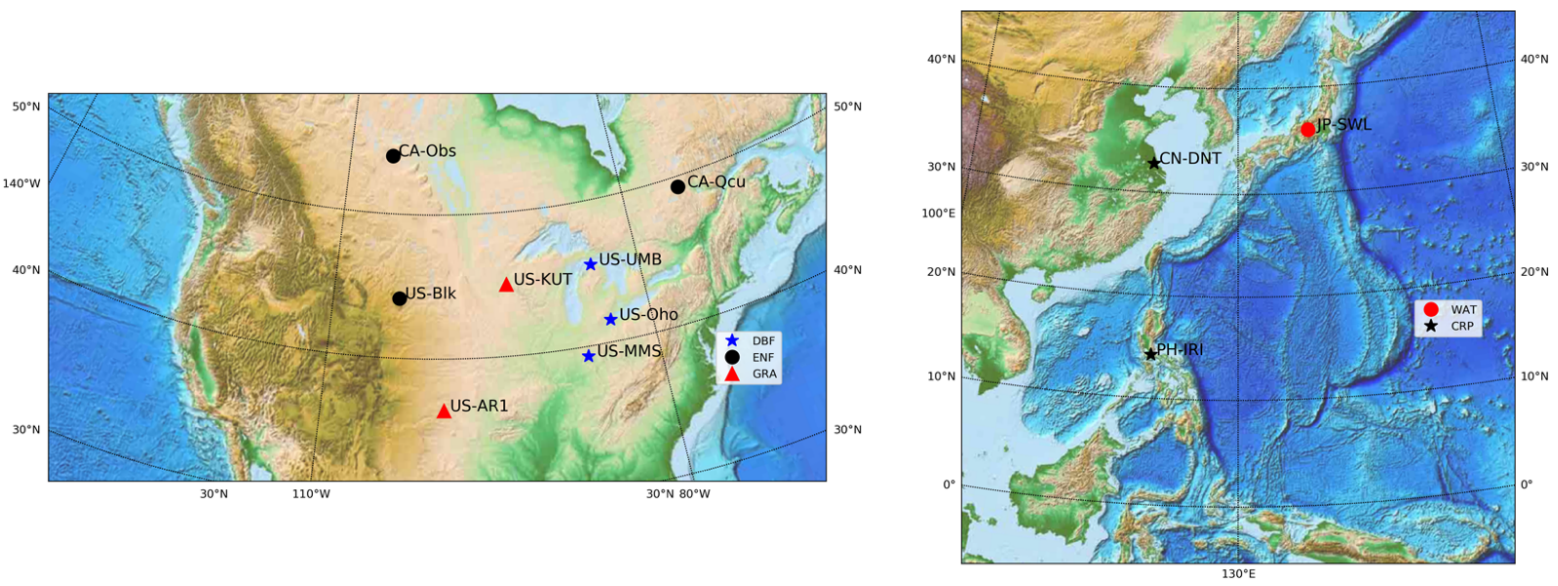

Figure 1: Location of sites (Table 3) analysed by vegetation type deciduous trees (DBF), evergreen trees 


\subsection{Determination of SUEWS parameters for pervious surfaces}

285 The processes and parameters of interest (Sect. 2.1, Table 1) are not completely independent

286 for vegetated surfaces as both $L A I$ and albedo influence surface conductance, hence $Q_{E}$. As

$287 L A I$ varies with vegetation type, season and climate (e.g. latitude, local site characteristics), this should be determined prior to albedo, surface conductance and $Q_{E}$; whereas neither bare soil nor water surfaces require $L A I$ (Fig. 2). At each site, the $L A I$ and albedo model parameters are derived with one year of data ('calibration') and evaluated with other years ('test') (Table 3, Fig. 3). Given limited data for the water site (JP-SWL, Table 3) the albedo is determined for April 2015 and evaluated for the remaining months (Fig. 3). Calibration data are used to derive $z_{0}$ and $z_{d}$ (Eq. 9) using the methods in Appendix B. These values are used in the $Q_{E}$ evaluation.

To assess the generality of the derived parameters (chosen based on minimized MAE) for a surface type, most are evaluated against both (Fig. 3): (a) another year at the same site, and (b) two independent sites using one year of data. However, lack of data prevents this for bare soil, crop, and water sites.

The Python package SuPy v2020.3.18 (Sun \& Grimmond 2019) with the calculation kernel SUEWS v2020a (Sun et al., 2020 ,Appendix A) is used for all simulations. The 5-min simulations are averaged to 30-min for consistency with the eddy covariance observations (Table 3). The complete Python source code (with comments) are provided at Omidvar et al.

302 (2020).

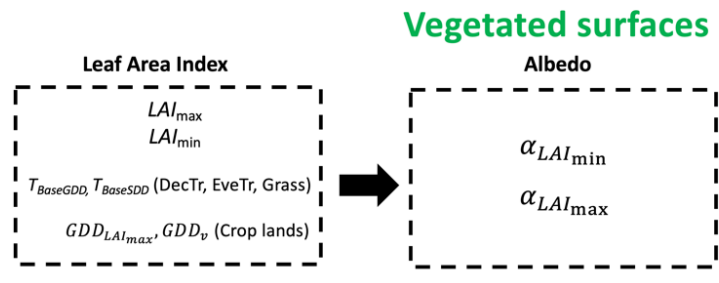

Bare Soil Surfaces

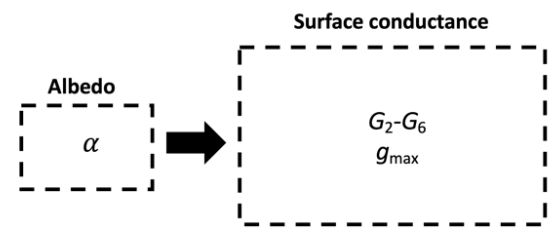

Water surfaces

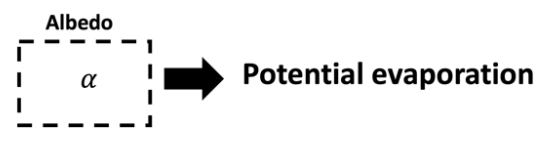

Figure 2: To obtain SUEWS parameters for LAI, albedo and surface conductance, the order indicated is required to be used. For notation see Table 1 
https://doi.org/10.5194/gmd-2020-148

Preprint. Discussion started: 17 July 2020

(c) Author(s) 2020. CC BY 4.0 License.

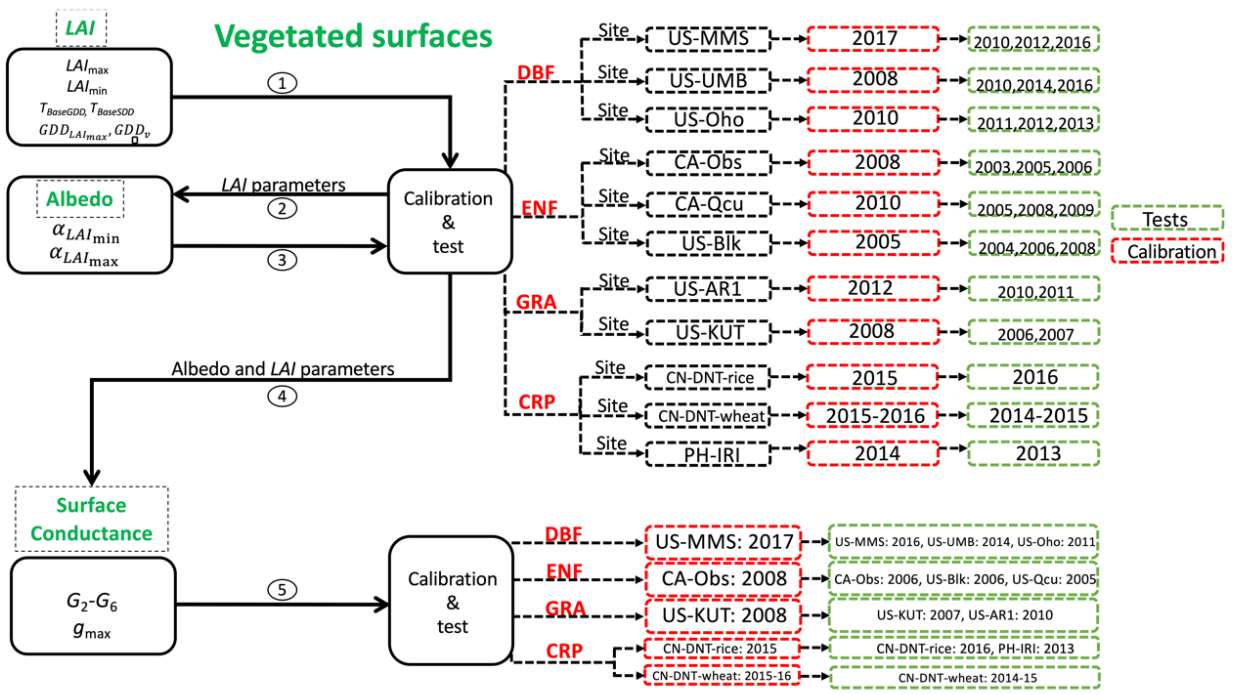

\section{Bare Soil Surfaces}

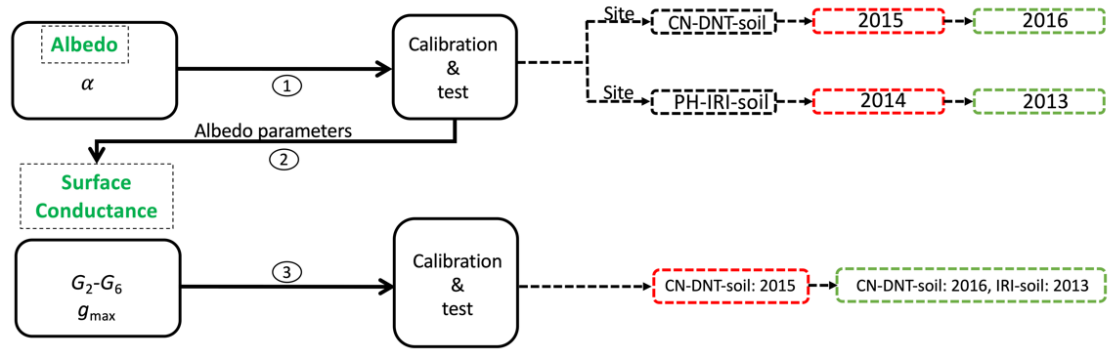

Water surfaces

306

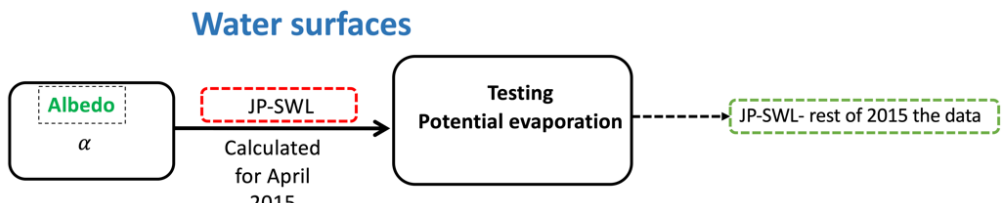

Figure 3: Sites and periods (Table 3) used to derive (calibrate) and evaluate (test) the parameters related to $L A I$, albedo and surface conductance for non-urban land types. Numbers in circles indicate order of calculation. Notation defined in Table 1.

\subsection{Evaluation metrics}

To evaluate the model output $\left(Y_{\text {mod }}\right)$ with observations $\left(Y_{\text {obs }}\right)$ for a number $(N)$ of data points the following metrics are used:

1) mean absolute error (MAE):

$$
\mathrm{MAE}=\frac{\sum_{i=1}^{n}\left|Y_{\text {mod }}-Y_{\mathrm{obs}}\right|}{N}
$$


2) mean bias error (MBE):

$$
\mathrm{MBE}=\frac{\sum_{i=1}^{n}\left(Y_{m o d}-Y_{o b s}\right)}{N}
$$

317 Both the MAE and MBE are ideally 0 (with units of parameter/variable assessed).

318 3) normalised MAE (nMAE):

$$
\mathrm{nMAE}=\frac{\mathrm{MAE}}{\mathrm{MAE}_{\text {calib }}}
$$

This is used to assess the model performance relative to data used to derive the parameters (calib). If nMAE > 1 the performance is poorer with the test data set than the calibration set (and vice versa).

To evaluate the evaporation, data are stratified by LA/ phenology: (1) leaf off/leaf on/transition for DBF, ENF and GRA sites (Sect. 3.1, 3.3) and (2) vegetative/reproductive/ripening for crops. Crop dates are available for CN-DNT (Table 3) but not for PH-IRI-rice. As different states are not available for the PH-IRI-rice, BSV and WAT sites $Q_{E}$ evaluation uses the entire period.

\section{Results and Discussion}

\subsection{LAI parameters}

Fig. 4 shows how different parameters control the $L A /$ dynamics (Eq. 3 ) at the deciduous forest site US-MMS (Table 3, Fig. 1) in 2017. At this site, LAl begins to increase from its minimum (0.5 $\mathrm{m}^{2} \mathrm{~m}^{-2}$ ) as the daily mean air temperature $\left(T_{d}\right)$ increases. As $T_{d}$ increases above $T_{\text {BaseGDD }} L A I$ increases to its maximum (i.e. 5). $L A /$ remains constant until $T_{d}$ goes below $T_{B a s e S D D}$ when $L A l$ starts decreasing until it reaches the minimum (i.e. 0.5). Whereas for rice (Fig. 5, CN-DNT site) the $L A$ / evolution from planting has a short peak period with almost symmetric ascending and descending parts. Given this different behaviour in $L A /$ evolution between crops and other vegetation types, two different forms (Eq. 3 and 5 ) are used.

Across all sites and years, the calculated $L A I$ (Eq. 3, Table 4 parameters) have good agreement with the MODIS LAI product (Sect. 2.1.1) (Fig. 6, 7). Based on entire years, all MAE are less than $0.67 \mathrm{~m}^{2} \mathrm{~m}^{-2}$ and the MBE are between -0.36 and $0.16 \mathrm{~m}^{2} \mathrm{~m}^{-2}$ (Table D1). The largest deviation from the MODIS LAl occurs at a grassland site (US-AR1) in 2011. A possible explanation for this may be a lack of rain, as in 2011, US-AR1 received half the rainfall of the other years, leading to larger soil moisture deficits (cf. 2010, 2012 (calibration)) (Fig. 8). This 
344 important role of rainfall and soil moisture in moderating $L A I$ dynamics with shallow vegetation

345 roots is also found by Bobée et al. (2012).

346 As expected, deciduous tree (DBF) sites have the largest variation in $L A$ l among the vegetated areas whereas grass has the smallest (Fig. 6, Table 4). However, the LAl variation at the evergreen sites (ENF) indicates that assuming a constant $L A /$ would result in poor predictions of albedo and consequently turbulent heat fluxes. Consistent with Liu et al. (2013) and Alemu \& Henebry (2016), for each vegetation type $T_{B a s e G D D}$ and $T_{B a s e S D D}$ generally decrease with increase in latitude (Table 3,4). However, CA-Obs has slightly larger values than CA-Qcu despite its higher latitude.

For both rice and wheat Eq. 5 performs well (Fig. 9, Table D1). The sharp decrease of $L A /$ after its peak in both rice and wheat is captured (Fig. 9a-c). For these crops, the MAE is $<0.53 \mathrm{~m}^{2} \mathrm{~m}^{-}$ ${ }^{2}$ and MBE is between -0.31 and $0.19 \mathrm{~m}^{2} \mathrm{~m}^{-2}$.

Generally, both Eq. 3 and 5 perform similarly when derived and evaluated (Fig. 7c, 9d). This suggests the $L A /$ calibration parameters from other years can be used. Recommended values are given in Sect. 4. Although Eq. 3 performance varies between calibration and test sites with phenology, no general trend is found (Fig. 7c).

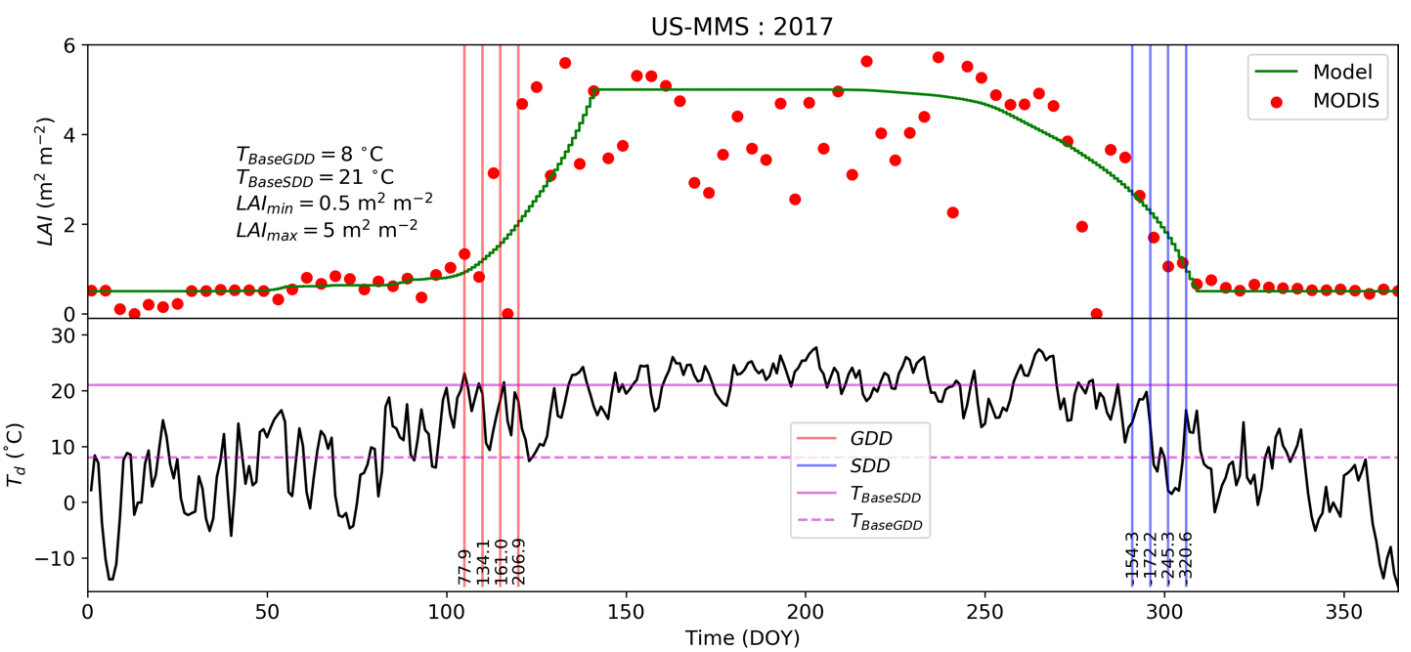

Figure 4: Deciduous forest (US-MMS 2017, Table 3) (a) LAI $\left(\mathrm{m}^{2} \mathrm{~m}^{-2}\right)$ modelled (Eq. 3) and from MODIS (Myneni et al. 2015) with values of $T_{\text {BasesDD }}, T_{\text {BaseGDD }}, L A I_{\min }$ and $L A I_{\max }$; and (b) $T_{d}$ (Eq. 4). Vertical lines (5 days apart) give GDD (red) and $S D D$ (blue) values $\left({ }^{\circ} \mathrm{C}\right.$ ) relative to $T_{B a s e G D}$ (solid) and $T_{\text {BasesDD }}$ (dashed) (horizontal purple lines, ${ }^{\circ} \mathrm{C}$ ). Notation is given in Table 1. 
https://doi.org/10.5194/gmd-2020-148

Preprint. Discussion started: 17 July 2020

(c) Author(s) 2020. CC BY 4.0 License.

365

366

367

368



Figure 5: Rice field (CN-DNT-2015 from June 10 (planting) to November 7 (harvest)) LAl: modelled (Eq.

$$
\text { 5) and MODIS (Myneni et al. 2015) with values of } G D D_{L A I_{\max }}\left({ }^{\circ} \mathrm{C}\right), G D D_{L A I_{\min }}\left({ }^{\circ} \mathrm{C}\right), L A l_{\min }\left(m^{2} \mathrm{~m}^{-2}\right)
$$

and $L A I_{\max }\left(\mathrm{m}^{2} \mathrm{~m}^{-2}\right)$; and $G D D_{d}$ (right axis, ${ }^{\circ} \mathrm{C}$ ). Notation is given in Table 1.
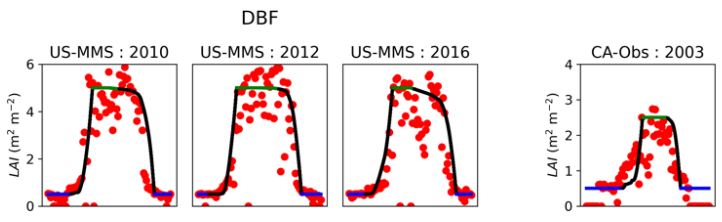

$$
\text { ENF }
$$
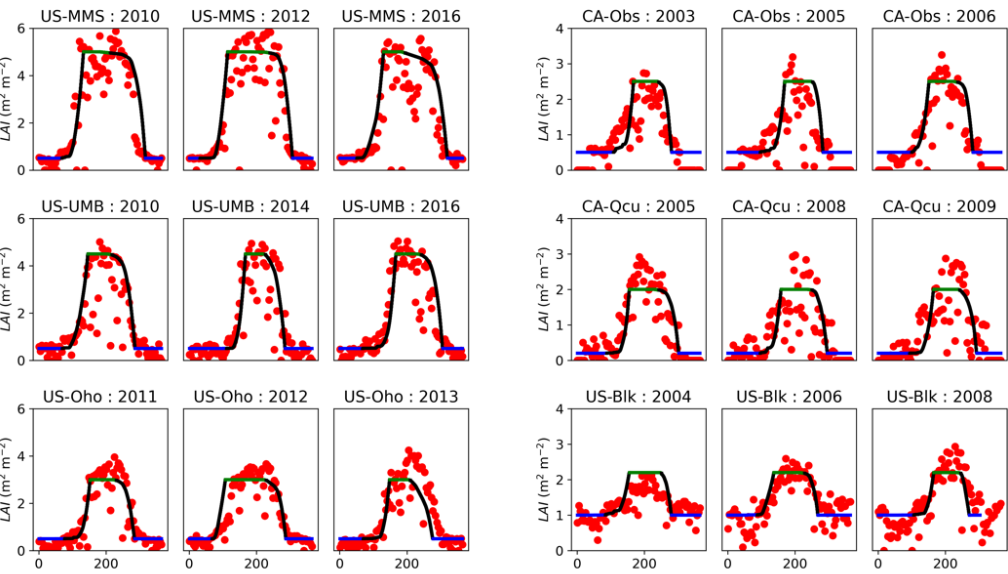

a.,

US-Oho: 2013
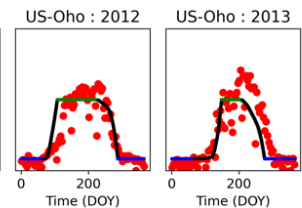

CA-Qcu : 2008
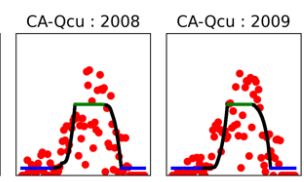

US-BIk : 2006
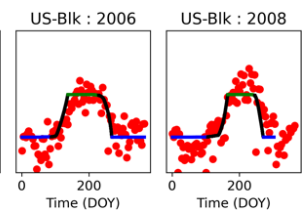

GRA
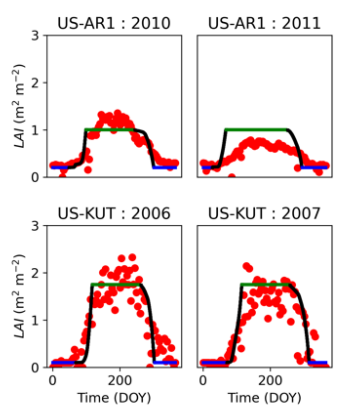

- Model-leaf off period

- Model-transitional period

- Model-leaf on period

- MODIS

Figure 6: Comparison of LAI $\left(\mathrm{m}^{2} \mathrm{~m}^{-2}\right)$ calculated (lines, Eq. 3, Table 4 parameters) and MODIS (dots, Myneni et al. 2015) for deciduous (DBF), evergreen (ENF) and grass (GRA) sites (Table 3, Fig.3) for different years with modelled maxima (green), leaf off (blue), and transitional growth/senescence (black) periods shown. 
https://doi.org/10.5194/gmd-2020-148

Preprint. Discussion started: 17 July 2020

(c) Author(s) 2020. CC BY 4.0 License.
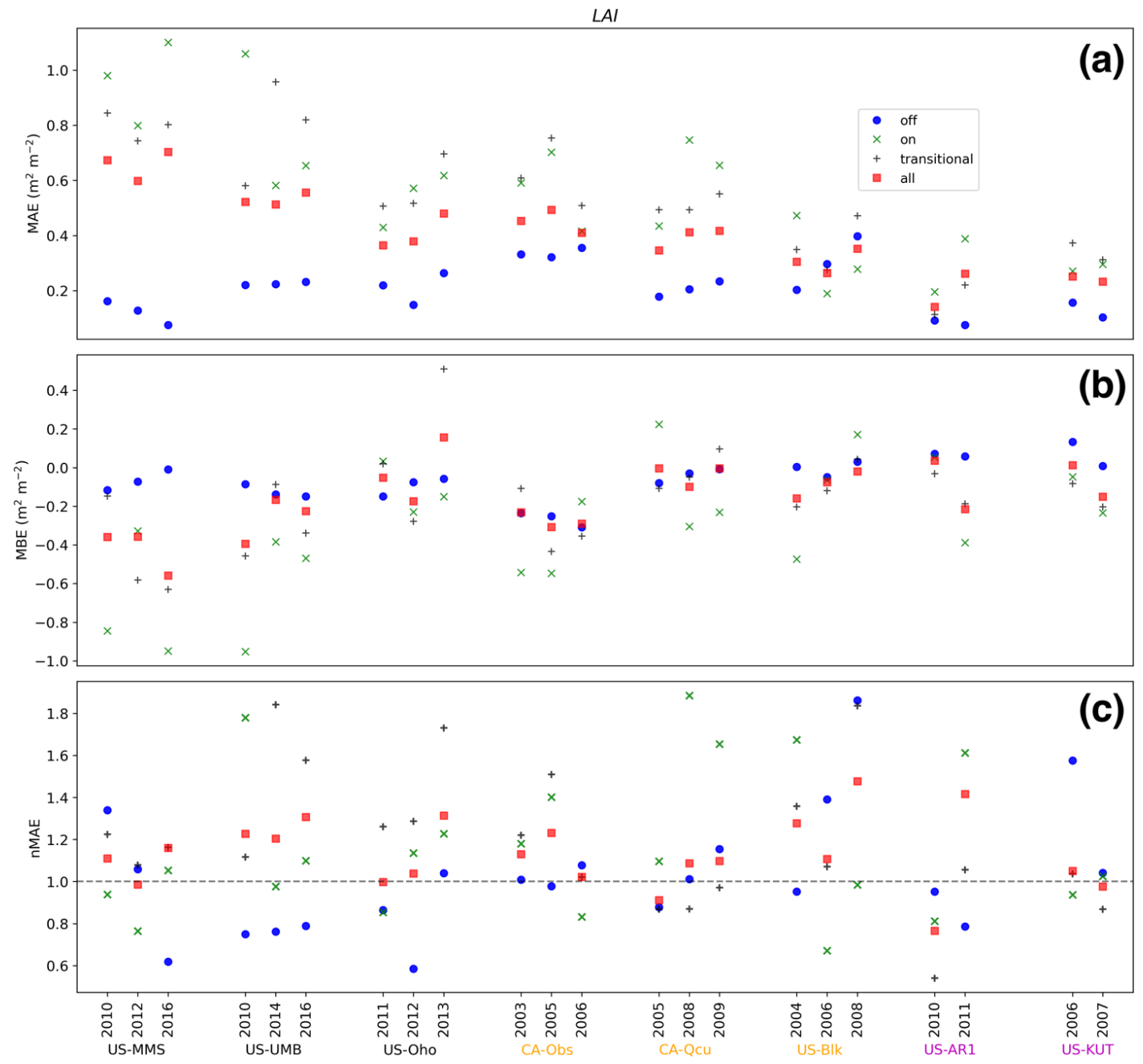

Figure 7: Modelled LAI (Eq. 3, Table 4 parameters) evaluated using MODIS (Myneni et al., 2015) for entire year (all), leaf on period (maxima), leaf off period (minima), and transitional period (growth/senescence period) for DBF (black x-axis label), ENF (yellow) and GRA (purple) sites. Performance metrics (Sect. 2.4) a: MAE b: MBE c: nMAE (Sect. 2.4) 
https://doi.org/10.5194/gmd-2020-148

Preprint. Discussion started: 17 July 2020

(c) Author(s) 2020. CC BY 4.0 License.

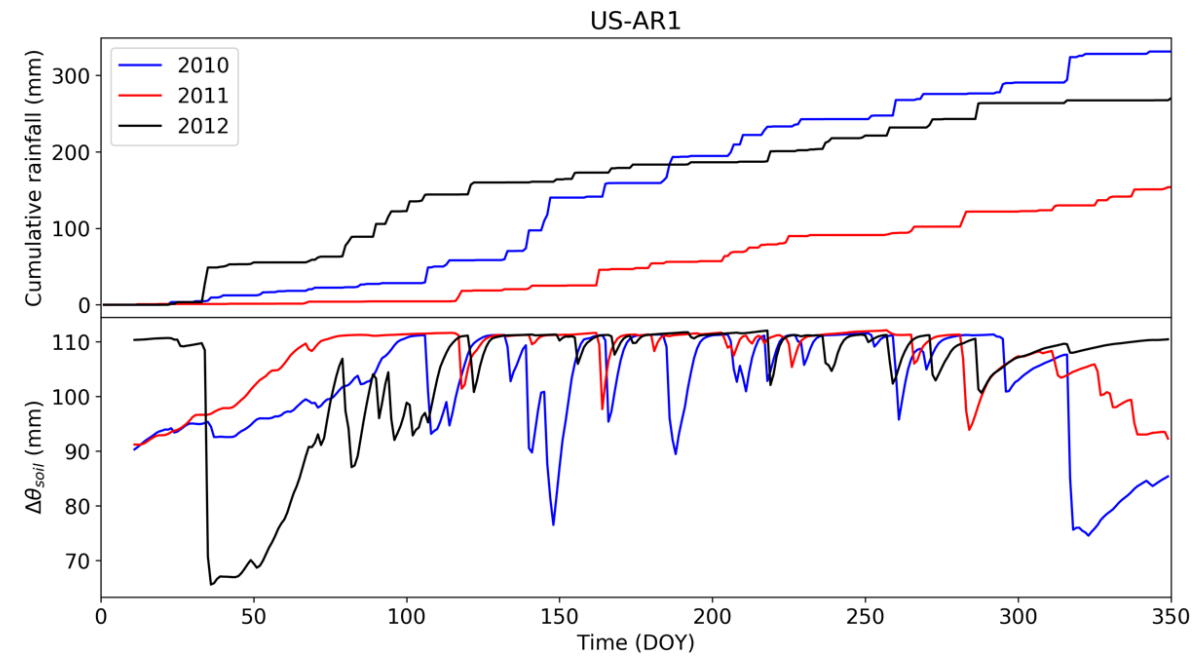

Figure 8: Grassland site (US-AR1) (a) cumulative rain and (b) SUEWS modelled soil moisture deficit $\left(\Delta \theta_{\text {soil }}\right)$ for three years: 2012 (calibration), 2010 and 2011 (test years). SUEWS spun up for each year using the same year data until the soil moisture deficit converges.
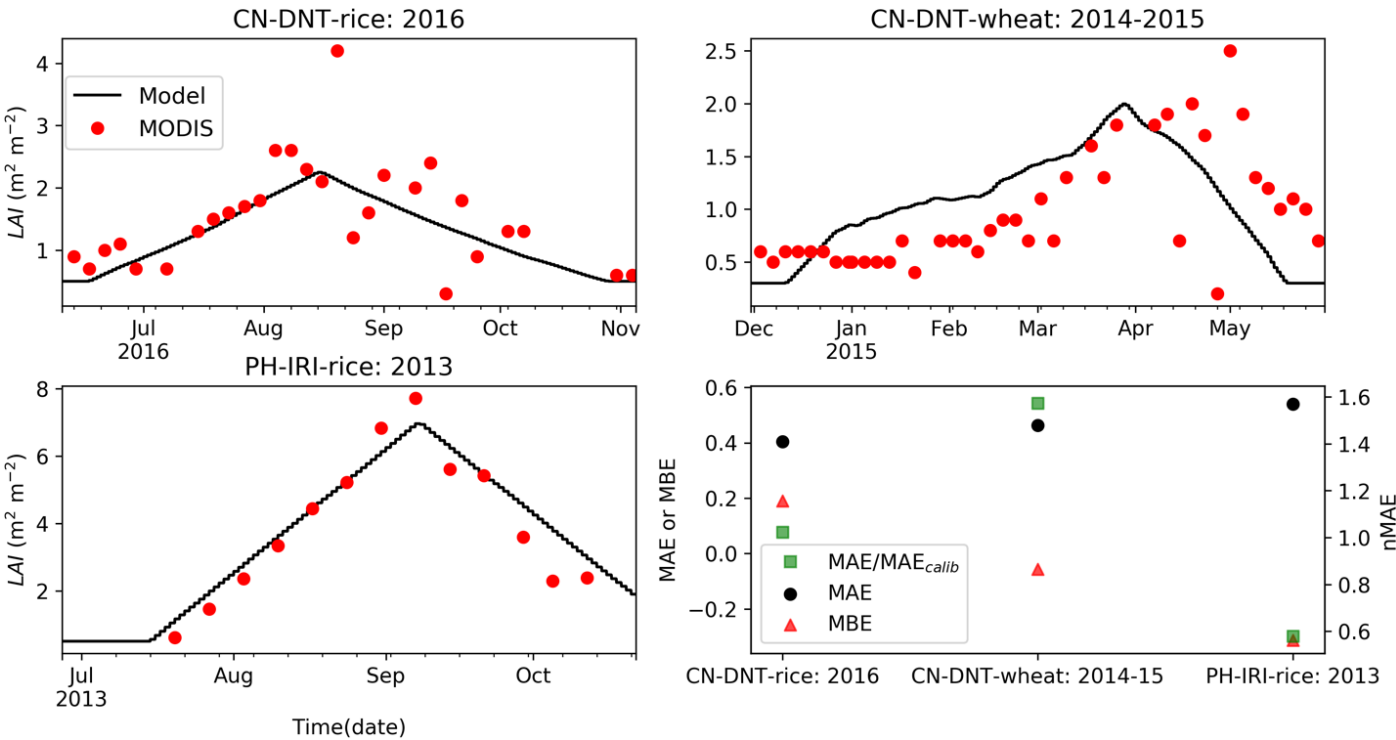

Figure 9: Crop site (Table 3) LAI $\left(\mathrm{m}^{2} \mathrm{~m}^{-2}\right)$ results a-c: using Eq. 5 with Table 4 parameters (lines) and MODIS (dots, Myneni et al., 2015) by time and site (Table 3, Fig.3); and d: evaluation statistics (Sect. 2.4). 
393

Table 4: Parameters derived for LAl using Eq. 3 (DBF, ENF, GRA) and Eq. 5 (RIC,WHT) and albedo (Eq. 6). Bare soil (BSV) $\alpha_{\text {LAImin }}$ is derived from the first 4 weeks of CN-DNT-rice. Water (WAT) is only for JP-SWL. Crop site air temperature at planting $\left(T_{\text {plant }}\right){ }^{*}$ is the 5 day mean.

\begin{tabular}{|c|c|c|c|c|c|c|c|c|}
\hline Site & Cover & LAI $_{\min }$ & LAI $_{\max }$ & $T_{\text {BaseSDD }}$ & $T_{\text {BaseGDD }}$ & & $\alpha_{\text {LAI }_{\min }}$ & $\alpha_{\text {LAI } \max }$ \\
\hline & & $\mathrm{m}^{2} \mathrm{~m}^{-2}$ & $\mathrm{~m}^{2} \mathrm{~m}^{-2}$ & ${ }^{\circ} \mathrm{C}$ & ${ }^{\circ} \mathrm{C}$ & & - & - \\
\hline US-MMS & DBF & 0.5 & 5.0 & 21 & 8 & & 0.10 & 0.14 \\
\hline US-UMB & DBF & 0.5 & 4.5 & 20 & 6 & & 0.10 & 0.14 \\
\hline US-Oho & DBF & 0.5 & 3.0 & 21 & 8 & & 0.10 & 0.14 \\
\hline CA-Obs & ENF & 0.5 & 2.5 & 15.0 & 5 & & 0.08 & 0.07 \\
\hline CA-Qcu & ENF & 0.2 & 2.0 & 11 & 2 & & 0.08 & 0.15 \\
\hline US-BIk & ENF & 1.0 & 2.2 & 16 & 5 & & 0.08 & 0.07 \\
\hline US-AR1 & GRA & 0.2 & 1.0 & 20 & 5 & & 0.14 & 0.19 \\
\hline US-KUT & GRA & 0.1 & 1.7 & 13 & 3 & & 0.18 & 0.21 \\
\hline & & & & $T_{\text {plant }}$ & $G D D_{v}$ & $G D D_{\text {LAI }}$ & & \\
\hline & & & & ${ }^{\circ} \mathrm{C}$ & ${ }^{\circ} \mathrm{C}$ & ${ }^{\circ} \mathrm{C}$ & & \\
\hline CN-DNT & RIC & 0.5 & 2.25 & $22.5^{*}$ & 135 & 1635 & 0.10 & 0.17 \\
\hline CN-DNT & WHT & 0.3 & 2.0 & $9.0^{*}$ & 90 & 770 & 0.12 & 0.18 \\
\hline PH-IRI & RIC & 0.5 & 7 & $29.0^{*}$ & 475 & 1970 & 0.09 & 0.18 \\
\hline JP-SWL & WAT & - & - & - & - & - & 0.05 & - \\
\hline CN-DNT & BSV & - & - & - & - & - & 0.10 & - \\
\hline
\end{tabular}

\subsection{Albedo parameters}

The daily albedo simulated with Eq. 6 (Table 4 parameters) clearly shows similar intra-annual evolution as the observations (Fig. 10, 11, snow-free periods, $\alpha<0.3$ ). Some sites (e.g. CA-Qcu) have an $\alpha \sim 0.85$ during snow. Although the snow flags (Sect. 2.1.2) do not identify all snow days (i.e. high albedo), they approximately indicate snow periods.

As our sites are snow-free between May and October (Fig. 10, F1), the independent evaluations use this period (except for crops). The crops are evaluated between planting and harvest (Fig. 11). Overall, the modelled and observed albedos are in good agreement (Fig. 12, Table D2) during the snow-free periods (May-October for AmeriFlux sites, and entire period for other sites) with MAE $<0.025,-0.012<$ MBE $<0.025$ and $0.5<\operatorname{nMAE}<1.6$ (Fig. 12). Water $(0.05)$ and bare soil ( 0.10 ) albedo are treated as constants (Table 4, consistent with Gascoin et al. (2009) and Nunez et al. (1972)). 
https://doi.org/10.5194/gmd-2020-148

Preprint. Discussion started: 17 July 2020

(c) Author(s) 2020. CC BY 4.0 License.

(c) (i)

DBF

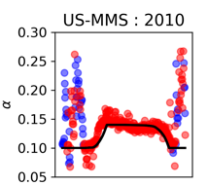

US-UMB : 2010

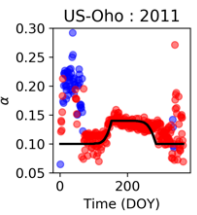

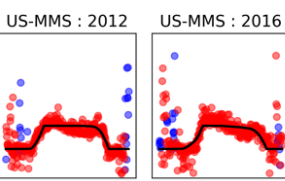
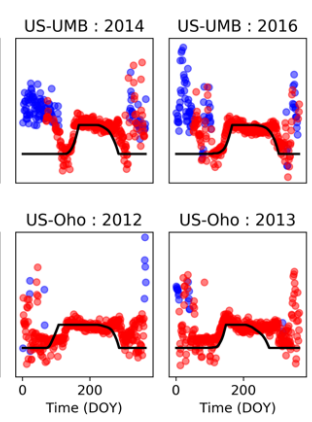

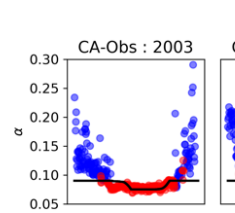

ENF
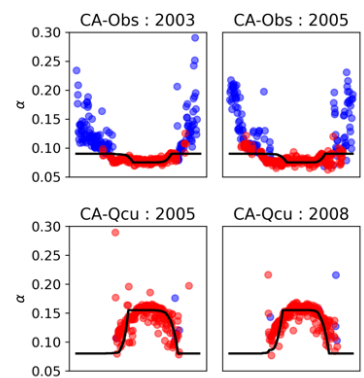

CA-OCu : 2008
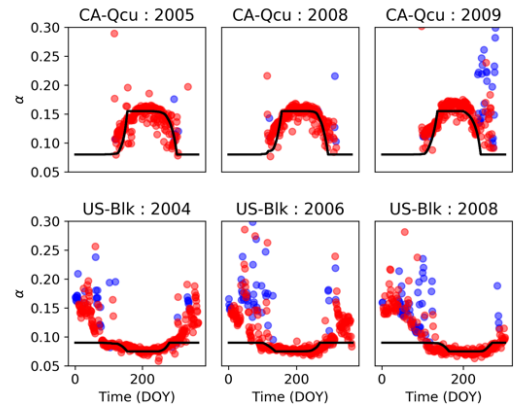

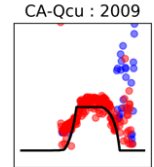

GRA
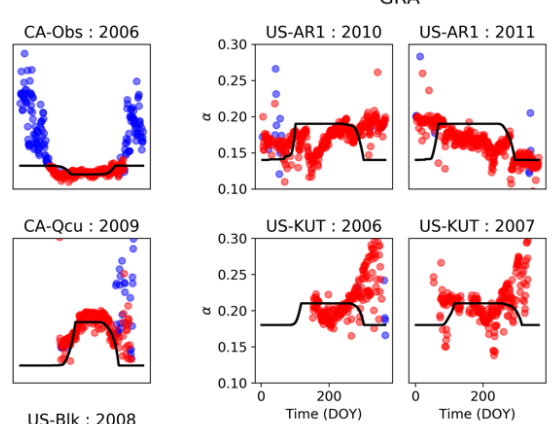

- Model

- Obs-snow detected

- Obs-snow not detected
407

408

409

410

411

412

Figure 10: Modelled (Eq. 6, lines) and observed (Sect. 2.1.2) daily albedo by time (day of year, redsnow free, blue - snow-covered, Sect. 2.3) for different vegetation types (Table 3). Note y-axis (albedo) varies between vegetation types.

CN-DNT-rice: 2016
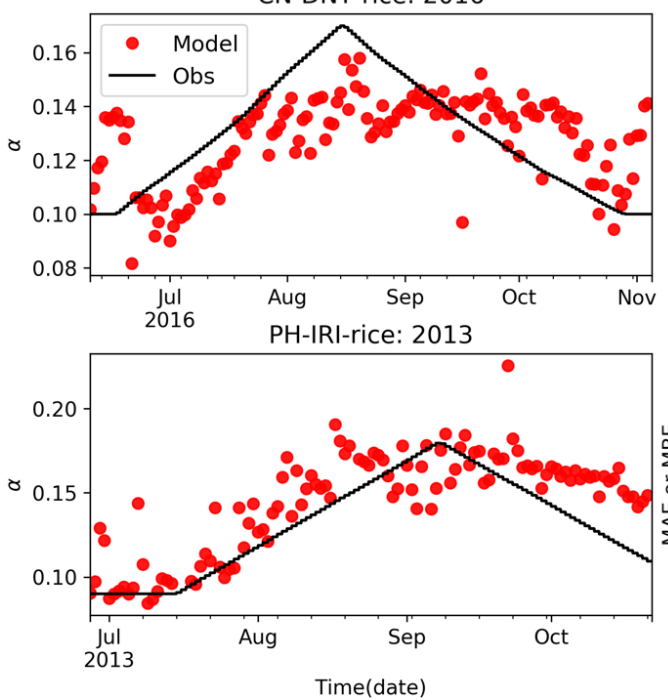

CN-DNT-wheat: 2014-2015
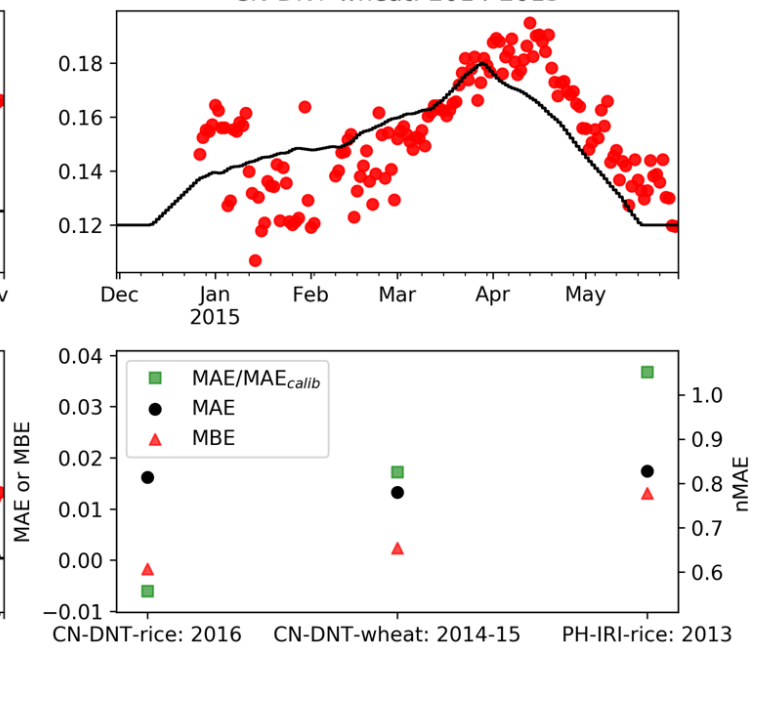

Figure 11: Daily crop albedo a-c: modelled (Eq. 6 with Table 4 parameters, lines) with observations by time (date) for three cases (Table 3), and d: evaluation statistics. 
https://doi.org/10.5194/gmd-2020-148

Preprint. Discussion started: 17 July 2020

(c) Author(s) 2020. CC BY 4.0 License.

Albedo
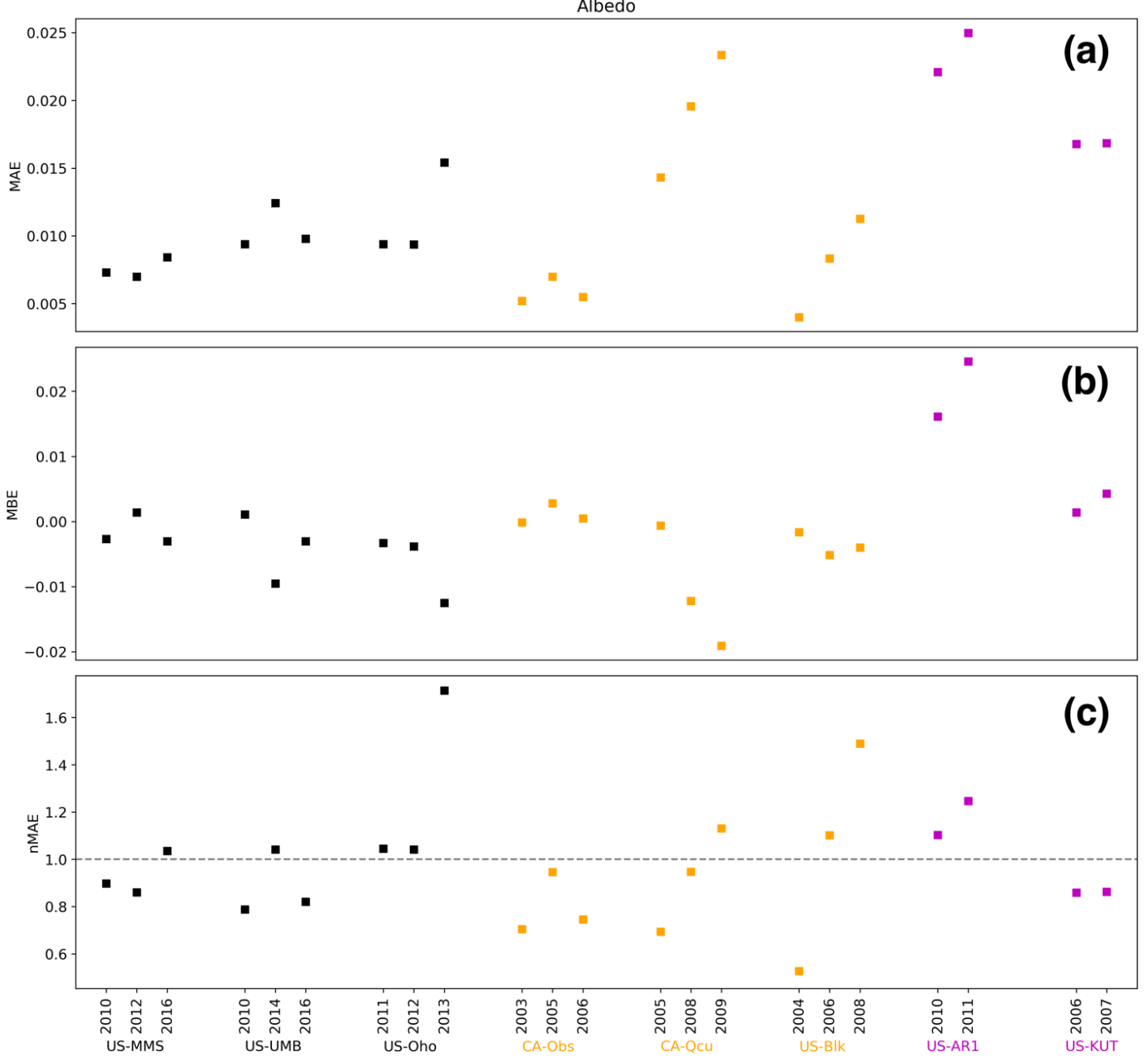

Figure 12: As Fig. 7, but for albedo assessed during a snow free period (May-October).

\section{$415 \quad 3.3 \quad$ Surface conductance parameters}

416 To model $Q_{E}, g_{\max }$ and $\left[G_{2}-G_{6}\right]$ are essential (Sect. 2.1.4). Here observed $K_{\downarrow}, T_{a}, \Delta q$ and

417 modelled $L A I$ (Fig. 2, 3) and $\Delta \theta_{\text {soil }}$ are used when fitting the parameters (Table 5). The values

418 obtained for different pervious land cover types are summarised in Table 5. $G_{2}$ (related to $K_{\downarrow}$ ), $G_{5}$

419 (related to $T_{a}$ ) and $G_{4}$ (related to $\Delta q$ ) do not vary substantially among different land types. $G_{6}$

420 (related to $\Delta \theta_{\text {soil }}$ ) is quite similar for DBF, ENF and GRA but varies for other land cover types.

421 However, $g_{\max }$ varies between all the land cover types. 
422 Using the derived parameters (Table 5), the SUEWS ability to predict $Q_{E}$ is assessed across the 423 test sites and years (Fig. 13, 14; Table D3). In general, for the DBF, ENF and GRA sites the 424 MAE (for all LAl states) is less than $58.5 \mathrm{~W} \mathrm{~m}^{-2}$ (Table D3) with a slight overestimation for most 425 of the sites in the leaf-on period (e.g. US-MMS, CA-Obs, CA-Qcu; MBE: 8.8 to $40.4 \mathrm{~W} \mathrm{~m}^{-2}$; Fig. 426 14, Table D3). $Q_{E}$ is overestimated in the leaf-transitional period at US-AR1 (MBE $=8.1 \mathrm{~W} \mathrm{~m}^{-2}$ ) 427 and underestimated at US-KUT (MBE $=-18.2 \mathrm{~W} \mathrm{~m}^{-2}$ ). For CRP, WAT and BSV, the MAE of $428 Q_{E}$ is generally less than $44.5 \mathrm{~W} \mathrm{~m}^{-2}$. For WAT, the smaller nocturnal overestimation of $Q_{E}$ may 429 result from overestimation of nocturnal storage heat flux.

430 Multiple factors influence the $Q_{E}$ performance: over/under estimation of $L A I$ (modifying albedo 431 and conductance) at vegetated sites; over/under prediction of storage heat flux (from for 432 example, missing moisture feedbacks); and/or assuming homogeneous fetch around each site.

433 Compared with using urban specific parameters, such as those derived for London and

434 Swindon, Ward et al., 2016), those derived for non-urban land covers (Table 5) improve

435 SUEWS $Q_{E}$ performance (Appendix E): MAE is reduced (cf. MAE $E_{\text {Ward }}$ ) and $\mathrm{nMAE}$ is less than 436 one for all the sites (Fig. E2).

Table 5: Surface conductance (Eq. 13-16) parameters (sites, Fig. 3) derived for different land cover types. Note individual site values are not reported.

\begin{tabular}{|c|c|c|c|c|c|c|}
\hline Land cover & $\begin{array}{c}\boldsymbol{g}_{\text {max }} \\
\left(\mathbf{m ~ s}^{\mathbf{- 1}}\right)\end{array}$ & $\begin{array}{c}\boldsymbol{G}_{\mathbf{2}} \\
\left(\mathbf{W ~ m ~}^{-\mathbf{2}}\right)\end{array}$ & $\boldsymbol{G}_{\mathbf{3}}$ & $\boldsymbol{G}_{\mathbf{4}}$ & $\begin{array}{c}\boldsymbol{G}_{\mathbf{5}} \\
\left({ }^{\circ} \mathbf{C}\right)\end{array}$ & $\begin{array}{c}\boldsymbol{G}_{\mathbf{6}} \\
\left(\mathbf{m m}^{-\mathbf{1}}\right)\end{array}$ \\
\hline DBF & 89.9 & 104.10 & 0.16 & 0.57 & 25.92 & 0.028 \\
\hline ENF & 14.9 & 104.64 & 0.70 & 0.63 & 36.62 & 0.022 \\
\hline GRA & 24.2 & 104.85 & 0.49 & 0.61 & 36.63 & 0.022 \\
\hline RIC & 234.8 & 105.13 & 0.97 & 0.75 & 36.91 & 0.046 \\
\hline WHT & 747.5 & 104.45 & 0.16 & 0.70 & 37.37 & 0.048 \\
\hline BSV & 10.9 & 108.93 & 0.93 & 0.96 & 42.26 & 0.041 \\
\hline
\end{tabular}


https://doi.org/10.5194/gmd-2020-148

Preprint. Discussion started: 17 July 2020

(c) Author(s) 2020. CC BY 4.0 License.

(c) (i)

DBF

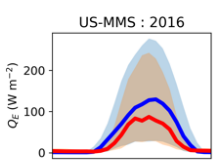

US-MMS : 2016(N $=5415)$

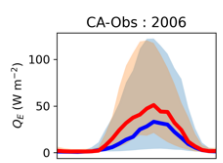

ENF

GRA
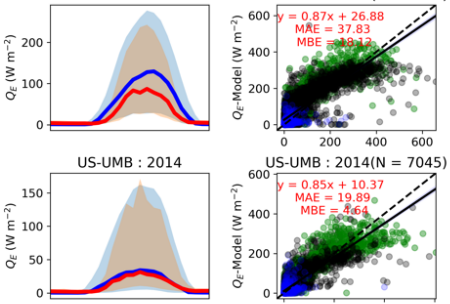

CA-Obs : 2006 $(\mathrm{N}=5740)$

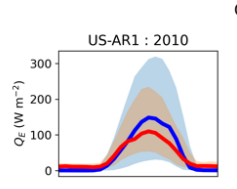

US-AR $1: 2010(\mathrm{~N}=7952)$

US-UMB : 2014(N = 7045)
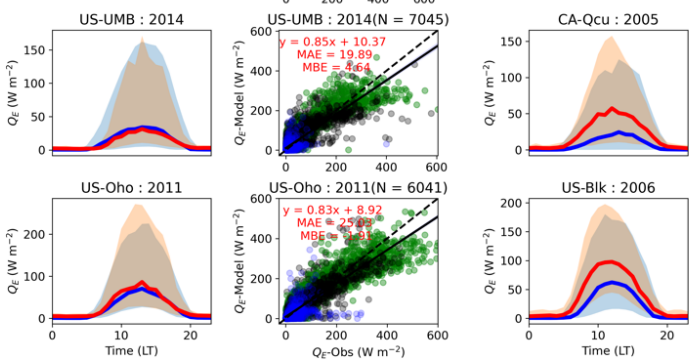

$\begin{array}{rrrr}0 & 200 & 400 & 600 \\ \text { US-Oho }: 2011(\mathrm{~N}=6041)\end{array}$
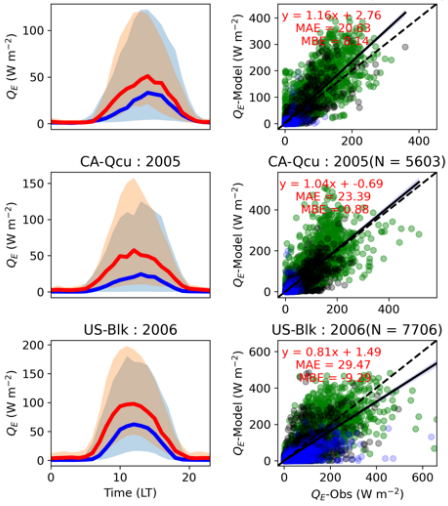

CA-OCu : $2005(\mathrm{~N}=5603)$
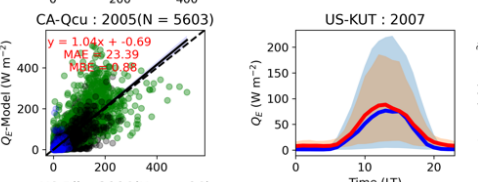

US-BIK : 2006(N $=7706$ )

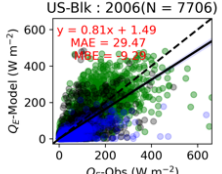

leaf-off

eaf-off

(vegeta

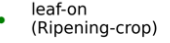

(Ripening-cror

- leaf-trans

- Entire period

$\mathrm{RIC}$

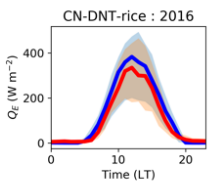

RIC
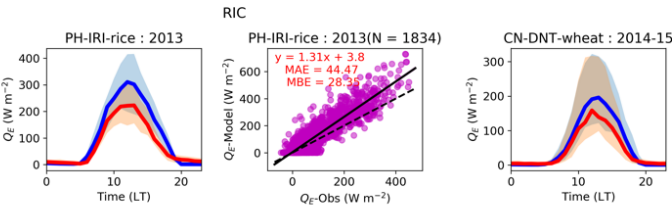

WHT

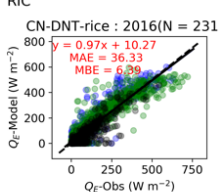

BSV

BSV
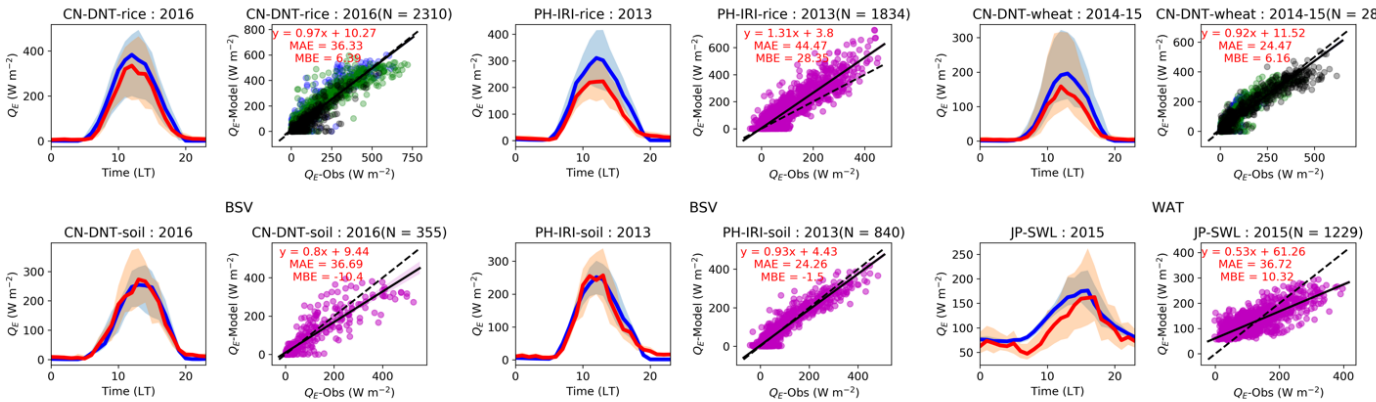

WAT
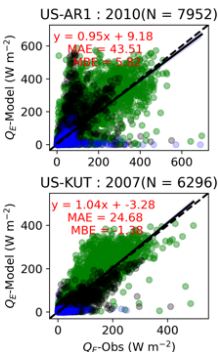

440

Figure 13: Latent heat flux for different sites (Table 3) calculated by SUEWS (Eq. 8 with Table 5 parameters) with annual diurnal pattern (median (lines) and interquartile range (shading)) for observed (red) and model (blue)) and scatter (dots, colour for LAl period, and $N$ is the number of data points). Note for water and flood period for rice, $r_{s}$ in Eq. 12 is zero and potential evaporation is calculated. 

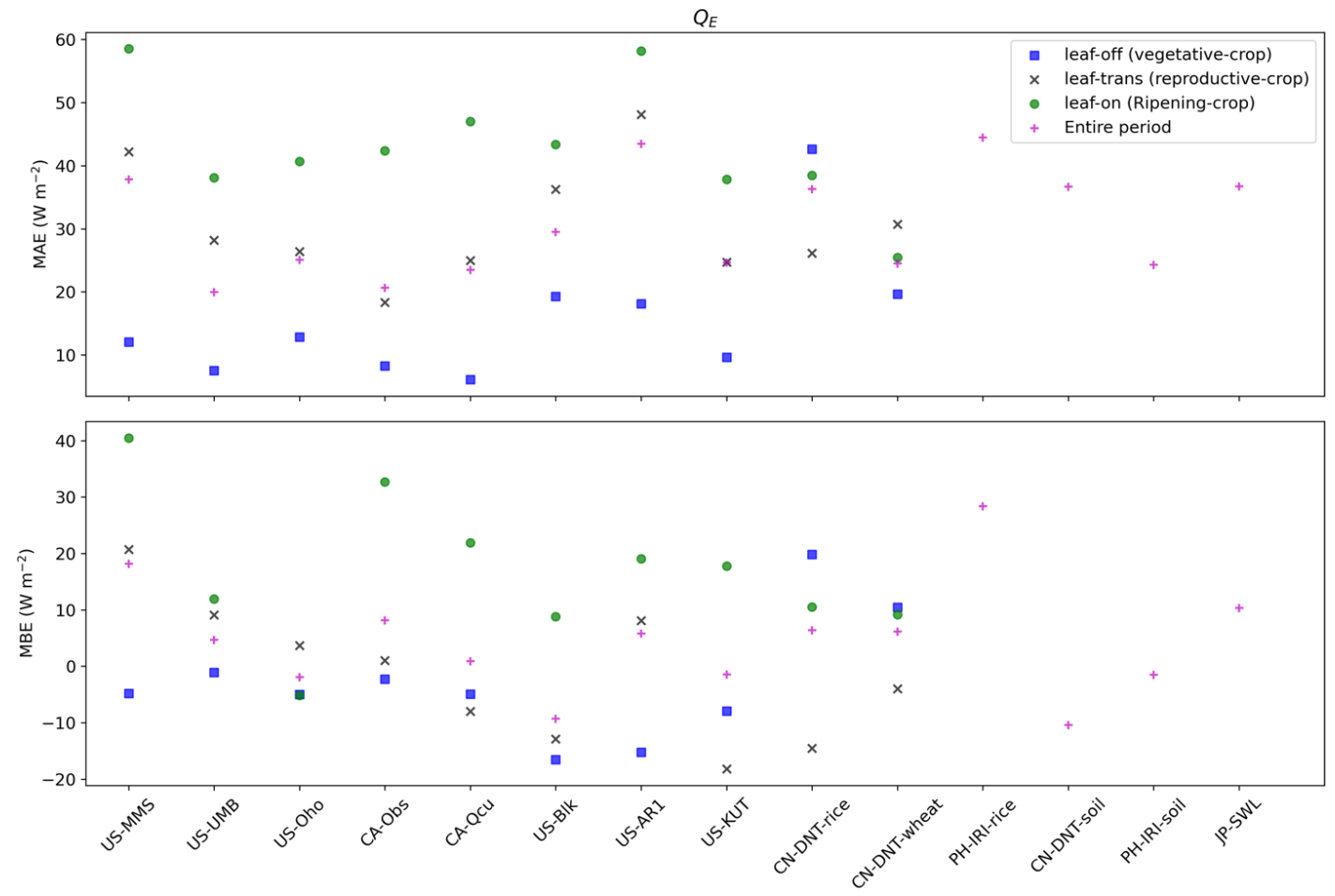

Figure 14: As Fig. 7, but for QE (Eq. 8, Table 5 parameters). Units $W m^{-2}$

\section{Concluding remarks}

449 New SUEWS parameters to simulate $L A I$, albedo and latent heat flux for different extensive pervious (i.e. non-urban) land covers are derived and independently evaluated. The Python Jupyter Notebooks protocol to derive the parameters is provided (Fig. 2, GitHub repository in Omidvar et al., 2020). This can be applied to other sites (or to other time periods at these sites). The order of parameter determination is critical ( $L A l \rightarrow$ albedo $\rightarrow$ surface resistance/ conductance, Fig 2,3 ) to ensure appropriate values are obtained.

Recommended values are given in Table 6 based on the variability of different parameters derived in this paper. In agreement with previous studies (e.g. Bobée et al., 2012), we find that soil moisture impacts $L A$ / for vegetation with shallow roots (e.g. grass). This feedback should be considered in future LAI modelling for SUEWS.

459 Using the derived (Table 2, 4, 5, 6) parameters or obtaining new values from the protocol 460 (Omidvar et al., 2020) gives broader applicability of SUEWS in non-urban areas and thus 
461 improves the model performance (cf. SUEWS runs using urban specific resistances, assuming

$\left.462 f_{i}=1\right)$. Use of these derived parameters in online SUEWS applications should improve

463 representation of land-atmosphere interactions.

464 Table 6: Recommended values for SUEWS parameters (Table 1) for pervious land cover where ranges in

$465 L A l$, albedo and roughness parameters indicate regional variations.

\begin{tabular}{|c|c|c|c|c|c|c|c|c|}
\hline \multicolumn{2}{|c|}{ Cover } & DBF & ENF & GRA & RIC & WHT & BSV & WAT \\
\hline \multicolumn{9}{|c|}{ LAI $^{\text {(Table 4) }}$} \\
\hline$L A I_{\min }$ & $\mathrm{m}^{2} \mathrm{~m}^{-2}$ & 0.5 & $0.2-1.0$ & $0.2-1.0$ & 0.5 & 0.2 & - & - \\
\hline$L A I_{\max }$ & $\mathrm{m}^{2} \mathrm{~m}^{-2}$ & $3.0-5.0$ & $2.0-2.5$ & $1.0-1.7$ & $1.7-7.0$ & 2.0 & - & - \\
\hline$T_{\text {BasesD }}$ & ${ }^{\circ} \mathrm{C}$ & $20-21$ & $11-16$ & $13-20$ & - & - & - & - \\
\hline$T_{\text {Basegt }}$ & ${ }^{\circ} \mathrm{C}$ & $6-8$ & $2-5$ & $3-5$ & - & - & - & - \\
\hline$G D D_{v}$ & ${ }^{\circ} \mathrm{C}$ & - & - & - & $135-475$ & 90 & - & - \\
\hline$G D D_{L A}$ & ${ }^{\circ} \mathrm{C}$ & - & - & - & $1635-1970$ & 770 & - & - \\
\hline
\end{tabular}

Albedo(Table 4) $^{(\text {T) }}$

\begin{tabular}{|c|c|c|c|c|c|c|c|c|}
\hline$\alpha_{\mathrm{LAI}_{\text {min }}}$ & - & 0.1 & 0.8 & $0.14-0.18$ & $0.09-0.10$ & 0.12 & 0.1 & 0.05 \\
\hline$\alpha_{\mathrm{LAI}_{\text {max }}}$ & - & 0.14 & $\begin{array}{c}0.07- \\
0.15\end{array}$ & $0.19-0.21$ & $0.17-0.18$ & 0.18 & - & - \\
\hline
\end{tabular}

Surface conductance ${ }^{(\text {Table } 5)}$

\begin{tabular}{|c|c|c|c|c|c|c|c|c|}
\hline$g_{\max }$ & $\mathrm{m} \mathrm{s}^{-1}$ & 33.5 & 21.8 & 13.8 & 276.8 & 660.8 & 10.9 & - \\
\hline$G_{2}$ & $\mathrm{~W} \mathrm{~m}^{-2}$ & 104.82 & 104.38 & 104.47 & 104.71 & 105.08 & 108.93 & - \\
\hline$G_{3}$ & - & 0.53 & 0.51 & 0.79 & 0.19 & 0.17 & 0.93 & - \\
\hline$G_{4}$ & - & 0.61 & 0.77 & 0.59 & 0.57 & 0.68 & 0.96 & - \\
\hline$G_{5}$ & ${ }^{\circ} \mathrm{C}$ & 36.3 & 36.28 & 37.24 & 36.46 & 36.76 & 42.26 & - \\
\hline$G_{6}$ & $\mathrm{~mm}^{-1}$ & 0.03 & 0.023 & 0.025 & 0.049 & 0.044 & 0.041 & - \\
\hline
\end{tabular}

OHM storage heat flux ${ }^{(\text {Table } 2)}$

\begin{tabular}{|c|c|c|c|c|c|c|c|c|}
\hline$a_{1}$ & - & 0.215 & 0.215 & 0.215 & 0.185 & 0.283 & 0.210 & 0.880 \\
\hline$a_{2}$ & $s$ & 0.325 & 0.325 & 0.325 & 0.615 & 0.784 & 0.902 & 0.370 \\
\hline$a_{3}$ & $\mathrm{~W} \mathrm{~m}^{-2}$ & -19.9 & -19.9 & -19.9 & -18.0 & -18.0 & -20.4 & -85.4 \\
\hline
\end{tabular}

Canopy water storage capacity ${ }^{(\text {Table } 2)}$

\begin{tabular}{c|c}
$\mathrm{S}_{i}$ & $\mathrm{~mm}$
\end{tabular}

$\mathrm{mm}$

1.3

1.9

\begin{tabular}{l|l}
1.9 & 1.9
\end{tabular}

Aerodynamic roughness (Table B1) by phenological state with $\mathrm{f}_{0}$ (Eq. B2) and $\mathrm{f}_{\mathrm{d}}(\mathrm{Eq}$. B3) parameters

\begin{tabular}{|c|c|c|c|c|c|c|c|c|c|}
\hline \multirow{3}{*}{ Zom } & \multirow{3}{*}{$\mathrm{m}$} & Leaf-off/ vegetative | 0.16 & $3.2-5.2$ & $0.3-5.1$ & $0.01-0.03$ & 0.24 & 0.12 & \multirow{3}{*}{0.002} & \multirow{3}{*}{0.0005} \\
\hline & & Trans./ reproductive| 0.18 & $3.9-5.5$ & $0.3-2.6$ & 0.01 & 0.19 & 0.2 & & \\
\hline & & \begin{tabular}{|l|l|} 
Leaf-on/ ripening & 0.18
\end{tabular} & $3.2-5.4$ & $1.8-2.4$ & $0.02-0.03$ & 0.55 & 0.38 & & \\
\hline \multirow{3}{*}{$Z_{d}$} & \multirow{3}{*}{$\mathrm{m}$} & Leaf-off/vegetative | 0.5 & $7.2-19.2$ & $3.7-6.5$ & $0.06-0.83$ & 0.32 & 0.14 & \multirow{3}{*}{0} & \multirow{3}{*}{ v } \\
\hline & & Trans/ reproductive 0.44 & $8.2-15.4$ & $2.2-6.6$ & $0.06-0.9$ & 0.39 & 0.45 & & \\
\hline & & Leaf-on/ripening $\quad 0.42$ & $8.0-10.9$ & $3.8-6.6$ & $0.06-0.83$ & 0.88 & 0.65 & & \\
\hline
\end{tabular}




\section{Appendix A: SUEWS developments included in v2020a}

\section{A.1 SUEWS surface temperature $\left(T_{s}\right)$ calculation}

469 At each time step, the surface temperature $T_{S}$ is calculated iteratively. First $T_{S}$ is estimated by NARP (net-all radiation parameterization) (Offerle et al., 2003; Loridan et al., 2011) as a function of air temperature $T_{a}$ (i.e., $T_{s}^{N A R P}=N A R P\left(T_{a}\right)$ ), then $T_{s}^{N A R P}$ is used to calculate $Q^{*}$ (via outgoing longwave radiation $L_{\uparrow}$ ). At the end of this iteration $(j), T_{S}$ is updated using sensible heat flux $Q_{H}$ and $T_{a}$ based on Monin-Obukhov similarity theory (MOST) to give a new value $T_{s, j}(j=1$, initial iteration). In subsequent iterations, the NARP-based estimation of $T_{s}$ is skipped and $T_{s, j-1}$ (i.e., previous iteration) is used in the $Q^{*}$ calculation and updated to $T_{s, j}$ (i.e. current iteration) using MOST. Once $\left|T_{s, j-1}-T_{s, j}\right|<$ a prescribed tolerance, then $T_{s}=T_{s, j}$ and iteration stops (or for $j=$ 20)

\section{A.2 SUEWS irrigation scheme for crops}

Automatic irrigation can be set (WaterUseMethod=1 in RunControl.nml file) to maintain the water availability at a specified level $h_{m}$ (e.g. a certain depth of ponding water for flood irrigation of rice or a particular soil moisture state of other crops; by setting column $h_{m}$ of SUEWS_Irrigation.txt file, in $\mathrm{mm}$ ). When it is a positive value it allows for flood irrigation (e.g. rice); otherwise, the soil moisture is maintained by irrigation at the maximum soil storage capacity minus $h_{m}$. The running water balance considering precipitation, irrigation, evaporation and runoff rates and the net change in storage is used to determine the irrigation needed (cf. Eq. 2) taking $h_{m}$ in to account. The irrigation needed $\left(\mathrm{I}_{\mathrm{N}}\right)$ is determined the last time step of the day. The $l_{e}$ water is applied the next day if needed (i.e. for $I_{N}>0 \mathrm{~mm}$ ) based on the rates specified by the user via the SUEWS automatic irrigation profile $f_{a}$. The automatic irrigation profile allows water to be supplied at the appropriate times of the day and intensity for the region. If the water is applied too rapidly (e.g. all in one 5 min timestep) unrealistic runoff will occur. At each time step, the $I_{N}$ is checked to confirm that water is still needed (as determined by $I_{N}$ at the end of the previous day). If there is need remaining at the end of the day this will be included in the end of day water balance calculation for the next day.

\section{A.3 SUEWS land cover adaptive $z_{0 v}$ scheme}


499 Otherwise $\left(f_{p r v}<1\right)$ Kawai et al. (2009) is used:

$$
z_{0 v}=z_{0 m} \exp \left(2-\left(1.2-0.9 f_{p r v}^{0.29}\right)\left(\frac{u_{*} z_{0 m}}{\mu}\right)^{0.25}\right)
$$

501 where $z_{0 m}$ is the roughness length for momentum, $u_{*}$ the friction velocity, and $\mu$ the molecular

502 diffusivity of air.

503

504

505

506

507

508

509

510

511

512

513

\section{Appendix B: Roughness length and zero-displacement height for momentum}

\section{B.1 Methods}

The roughness parameters $\left(z_{0 m}, z_{d}\right)$ are derived during neutral stability $\left(\mid\left(z_{m}-0.7 h_{v}\right) / L\right) \mid<0.01$, i.e.

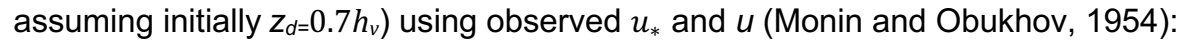

$$
u=\frac{u_{*}}{\kappa} \ln \left[\frac{z_{m}-z_{d}}{z_{0 m}}\right]
$$

These can also be obtained simply using a rule of thumb (Garratt 1991, Grimmond and Oke 1999):

$$
\begin{gathered}
z_{0, m}=f_{0, i} h_{v, i} \\
z_{d}=f_{d, i} h_{v, i}
\end{gathered}
$$

where $h_{v i}$ is the vegetation height for type $i$ and $f_{0, i}$ and $f_{d, i}$ depend on porosity of the vegetation type.

The same multi-objective evolutionary algorithm used to determine $G_{2}-G_{6}$ (Sect. 2.1.4), is applied with two objectives to optimize Eq. B1: (1) to minimize the normalized (n) standard deviation (SD) of observations (obs) of $u$ :

$$
\mathrm{nSD}=\frac{S D\left(u_{m o d}\right)-\mathrm{SD}\left(u_{o b s}\right)}{S D\left(u_{o b s}\right)}
$$

(2) to minimize the MAE of $u$ (Eq. 22).

As $L A /$ state changes both $z_{o m}$ and $z_{d}$ (e.g. Kent et al. $2017 \mathrm{~b}$ ) by modifying the porosity of the canopy, the three phenological states (leaf off, on and transition, Sect. 3.1) are considered. However, sufficient data ( $>20$, Grimmond et al. 1998) need to be used. By undertaking analysis by wind direction for sites that appeared to have variable results (based on modelled $u$ ) it is also possible to identify sites that have varying fetch by wind direction (e.g. CA-Qcu). This can be 
confirmed using visible wavelength satellite imagery. As CA-Qcu's fetch is found to vary, data are analysed with $10^{\circ}$ direction bins (for each $L A /$ state) with the median $z_{0 m}$ and $z_{d}$ used.

To obtain the parameters $f_{0, i}$ and $f_{d, i}$ (Eq. B2 and B3) vegetation heights are needed (Table 3). As crop height varies substantially through a season, where heights are available (e.g. C-DNT, Duan et al. 2020) these are used. However, for others only one height is used and $z_{0 m}, z_{d}$ are calculated for the entire growth period (e.g. PH-IRI). The training years (Table 3) are used to derive $z_{0 m}, z_{d}$ and subsequently $f_{0, i}$ and $f_{d, l}$. $0.16-0.18$ and $0.42-0.5$ (Fig. B.1) across phenological states. These values for each $L A /$ state
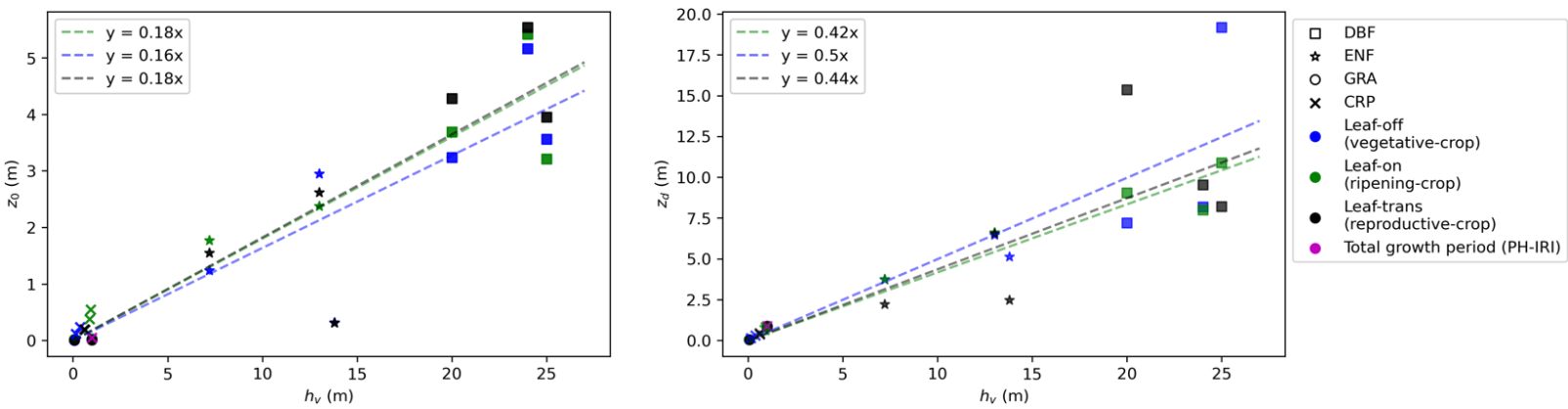

Figure B1: Micrometeorologically derived (Eq. B1) aerodynamic roughness parameters and vegetation height (Table 3) calculated for the calibration years by phenological state (Sect. 3.1): (a) Zom and (b) $z_{d}$. The crop states heights vary for CN-DNT (Duan et al. 2020) [rice: vegetative $=0.39 \mathrm{~m}$, reproductive $=0.64 \mathrm{~m}$, ripening $=0.93 \mathrm{~m}$; wheat: vegetative $=0.15 \mathrm{~m}$, reproductive $=0.58 \mathrm{~m}$ ripening $=0.86 \mathrm{~m}]$ but not for $\mathrm{Ph}-\mathrm{IRI}$.

The ability to predict $u$ is assessed for different sites with LAl/crop state using Eq. B1 and the derived $z_{0 m}$ and $z_{d}$ values (Table B1). These are in generally good agreement with observations

(Fig. B2), with MAE $<1.32 \mathrm{~m} \mathrm{~s}^{-1}$ and $-1.03<\mathrm{MBE}<1.22 \mathrm{~m} \mathrm{~s}^{-1}$. 
https://doi.org/10.5194/gmd-2020-148

Preprint. Discussion started: 17 July 2020

(c) Author(s) 2020. CC BY 4.0 License.
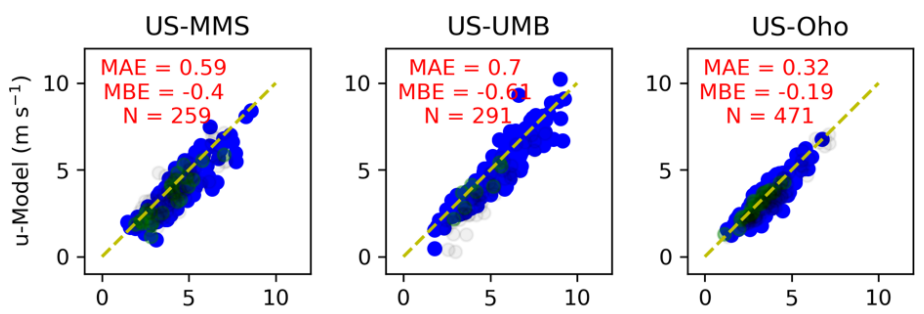

CA-Obs

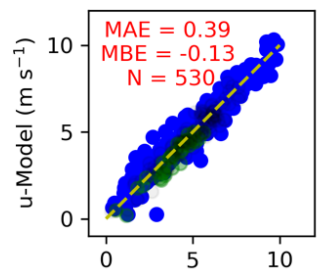

CA-Qcu

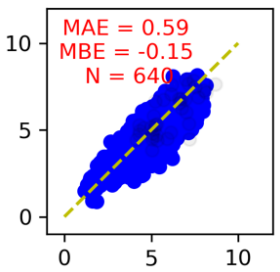

US-BIk
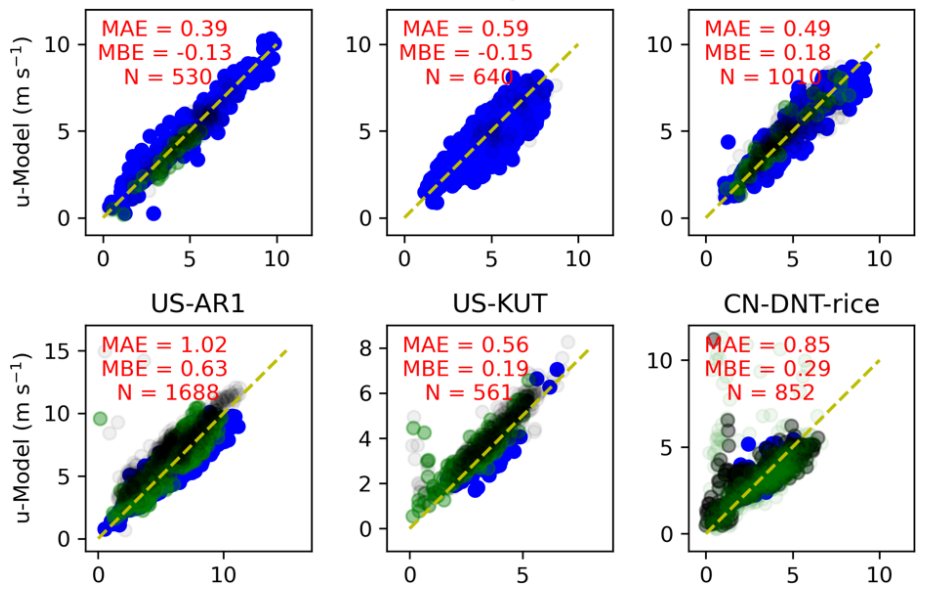

CN-DNT-wheat
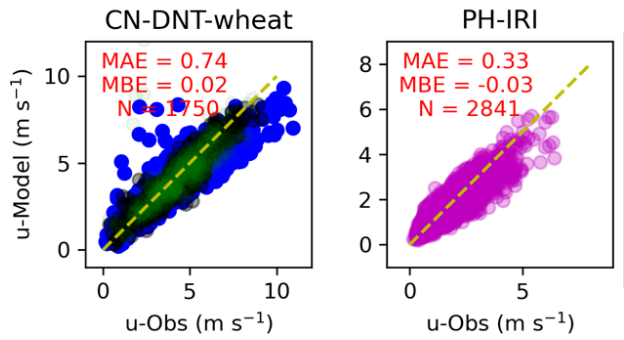

u-Obs $\left(\mathrm{m} \mathrm{s}^{-1}\right)$

-1-1

leaf-off

- (vegetative-crop)

leaf-on

- (Ripening-crop)

leaf-trans

(reproductive-crop)

Total growth period (PH-IRI)

Figure B2: Comparison of observed u (u-Obs) to modelled u (u-Model, zom and $z_{d}$ Eq. B1,Table B1) at the vegetated sites for all training years (Table 3) with number $(N)$ data points and phenology (Sect. 3.1) and CN-DNT crop states (Duan et al. 2020).

Table B1: Micrometeorological (Eq. B1) $z_{0 m}$ and $z_{d}$ for vegetation sites (Table 3) for number (N) data points for different phenology periods (Sect. 3.1) and for CN-DNT crop states (Duan et al. 2020). MAE $\left(m^{-1}\right)$ and MBE $\left(m s^{-1}\right)$ are calculated for $u$.

\begin{tabular}{|c|c|c|c|c|c|c|c|c|c|c|c|c|c|c|c|}
\hline & \multicolumn{4}{|c|}{ Leaf-off } & \multicolumn{4}{|c|}{ Leaf-trans } & \multicolumn{5}{c|}{ Leaf-on } \\
\hline site & $\begin{array}{c}z_{\text {Om }} \\
(\mathrm{m})\end{array}$ & $\begin{array}{c}z_{d} \\
(\mathrm{~m})\end{array}$ & $M A E$ & $M B E$ & $N$ & $\begin{array}{c}z_{0 m} \\
(\mathrm{~m})\end{array}$ & $\begin{array}{c}z_{d} \\
(\mathrm{~m})\end{array}$ & $M A E$ & $M B E$ & $N$ & $\begin{array}{c}z_{0 m} \\
(\mathrm{~m})\end{array}$ & $\begin{array}{c}z_{d} \\
(\mathrm{~m})\end{array}$ & $M A E$ & $M B E$ & $N$ \\
\hline US-MMS & 3.56 & 19.19 & 0.58 & -0.38 & 145 & 3.95 & 8.2 & 0.66 & -0.40 & 89 & 3.21 & 10.9 & 0.54 & -0.41 & 25 \\
\hline US-UMB & 3.24 & 7.22 & 0.58 & -0.44 & 221 & 4.28 & 15.36 & 1.03 & -1.03 & 48 & 3.69 & 9.06 & 0.50 & -0.36 & 22 \\
\hline US-Oho & 5.16 & 8.18 & 0.33 & -0.19 & 354 & 5.54 & 9.54 & 0.46 & -0.38 & 90 & 5.42 & 7.99 & 0.16 & 0.0 & 27 \\
\hline CA-Obs & 1.24 & 3.73 & 0.41 & 0.12 & 371 & 1.55 & 2.22 & 0.39 & -0.16 & 124 & 1.77 & 3.76 & 0.39 & -0.36 & 35 \\
\hline CA-Qcu & 0.32 & 5.14 & 0.58 & -0.14 & 602 & 0.31 & 2.47 & 0.72 & -0.16 & 38 & - & - & - & & - \\
\hline US-Blk & 2.95 & 6.46 & 0.45 & 0.12 & 727 & 2.62 & 6.56 & 0.58 & 0.22 & 230 & 2.38 & 6.63 & 0.44 & 0.20 & 53 \\
\hline US-AR1 & 0.03 & 0.83 & 0.82 & 0.28 & 938 & 0.01 & 0.9 & 1.32 & 1.22 & 442 & 0.03 & 0.83 & 0.91 & 0.38 & 308 \\
\hline
\end{tabular}




\begin{tabular}{|c|c|c|c|c|c|c|c|c|c|c|c|c|c|c|c|}
\hline US-KUT & 0.01 & 0.06 & 0.59 & -0.38 & 54 & 0.01 & 0.06 & 0.57 & 0.52 & 330 & 0.02 & 0.06 & 0.5 & 0.43 & 177 \\
\hline & \multicolumn{5}{|c|}{ Vegetative-crop } & \multicolumn{5}{|c|}{ Reproductive-crop } & \multicolumn{5}{|c|}{ Ripening-crop } \\
\hline CN-DNT-rice & 0.24 & 0.32 & 0.42 & 0.05 & 112 & 0.19 & 0.39 & 0.84 & 0.26 & 318 & 0.55 & 0.88 & 1.30 & 0.55 & 422 \\
\hline CN-DNT-wheat & 0.12 & 0.14 & 0.91 & 0.02 & 754 & 0.2 & 0.45 & 0.48 & -0.14 & 575 & 0.38 & 0.65 & 0.85 & 0.19 & 421 \\
\hline & \multicolumn{5}{|c|}{ Total Growth Period } & & & & & & & & & & \\
\hline PH-IRI-rice & 0.05 & 0.89 & 0.33 & -0.03 & 2841 & & & & & & & & & & \\
\hline
\end{tabular}

\section{Appendix C: Latent heat flux $\left(Q_{E}\right)$ in extremely cold conditions}

557 As the surface conductance (Eq. 12) has an air temperature dependency with limits (i.e. $T_{L}$ in 558 Eq. 15), we investigate the $T_{L}$ limit with $Q_{E}$ below $-10^{\circ} \mathrm{C}$ for different sites (Fig. C1). Given this 559 we use $T_{L}=-20^{\circ} \mathrm{C}$ for all sites as the limit when evaporation switches off in SUEWS.
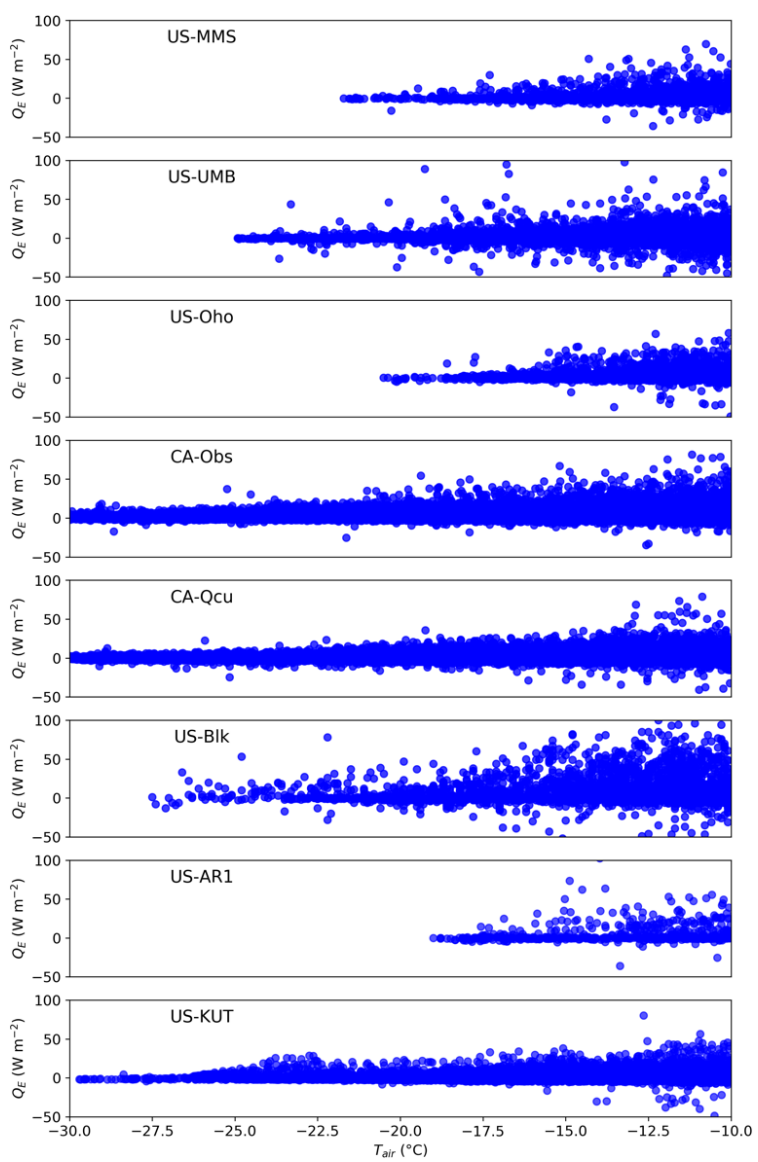

561 Figure C1: Latent heat flux $Q_{E}$ variation with air temperature $T_{a}$ when $T_{a}<-10^{\circ} \mathrm{C}$ at eight sites (Table 3). 
Sites (Table 3) used to evaluated (metrics Sect. 2.4) the parameters assessed LAI (Table D1), albedo (Table D2) and latent heat flux (Table D3).

Table D1: Evaluation of SUEWS modelled LAI (Eq. 3 or 5, with parameters Table 4) and MODIS LAI product (Myneni et al., 2015) for entire year (all), leaf on period (model LAl - maxima), leaf off period (LAI model - minima), and transitional period (growth/senescence period). Units: $\mathrm{m}^{2} \mathrm{~m}^{-2}$. $N$ is the number of data points in each period for each site

\begin{tabular}{|c|c|c|c|c|c|c|c|c|c|c|c|c|c|}
\hline \multirow{2}{*}{ site } & \multirow{2}{*}{ year } & \multicolumn{3}{|c|}{ All } & \multicolumn{3}{|c|}{ Leaf-off } & \multicolumn{3}{|c|}{ Transitional } & \multicolumn{3}{|c|}{ Leaf-on } \\
\hline & & MAE & MBE & $\mathbf{N}$ & MAE & MBE & $\mathbf{N}$ & MAE & MBE & $\mathbf{N}$ & MAE & MBE & $\mathbf{N}$ \\
\hline \multirow{3}{*}{ US-MMS } & 2010 & 0.67 & -0.36 & 94 & 0.16 & -0.12 & 30 & 0.84 & -0.15 & 44 & 0.98 & -0.84 & 20 \\
\hline & 2012 & 0.60 & -0.36 & 92 & 0.12 & -0.05 & 23 & 0.88 & -0.70 & 38 & 0.80 & -0.33 & 31 \\
\hline & 2016 & 0.70 & -0.56 & 91 & 0.08 & -0.01 & 24 & 0.80 & -0.63 & 51 & 1.10 & -0.95 & 16 \\
\hline \multirow{3}{*}{ US-UMB } & 2010 & 0.52 & -0.39 & 92 & 0.22 & -0.09 & 38 & 0.58 & -0.46 & 36 & 1.06 & -0.95 & 18 \\
\hline & 2014 & 0.51 & -0.17 & 92 & 0.22 & -0.14 & 48 & 0.96 & -0.09 & 29 & 0.58 & -0.38 & 15 \\
\hline & 2016 & 0.56 & -0.23 & 90 & 0.23 & -0.15 & 30 & 0.82 & -0.34 & 41 & 0.65 & -0.47 & 19 \\
\hline \multirow{3}{*}{ US-Oho } & 2011 & 0.36 & -0.05 & 94 & 0.22 & -0.15 & 40 & 0.51 & 0.02 & 34 & 0.43 & 0.03 & 20 \\
\hline & 2012 & 0.38 & -0.17 & 93 & 0.15 & -0.08 & 37 & 0.52 & -0.28 & 25 & 0.57 & -0.23 & 31 \\
\hline & 2013 & 0.48 & 0.16 & 93 & 0.24 & -0.04 & 40 & 0.74 & 0.54 & 37 & 0.62 & -0.15 & 16 \\
\hline \multirow{3}{*}{ CA-Obs } & 2003 & 0.45 & -0.23 & 91 & 0.33 & -0.24 & 47 & 0.61 & -0.11 & 25 & 0.59 & -0.54 & 19 \\
\hline & 2005 & 0.49 & -0.31 & 95 & 0.32 & -0.25 & 46 & 0.75 & -0.43 & 28 & 0.70 & -0.55 & 21 \\
\hline & 2006 & 0.41 & -0.29 & 93 & 0.35 & -0.31 & 46 & 0.51 & -0.35 & 25 & 0.42 & -0.17 & 22 \\
\hline \multirow{3}{*}{ CA-Qcu } & 20 & 0.35 & -0.03 & 92 & 0.20 & -0.13 & 38 & 0.48 & -0.13 & 32 & 0.43 & 0.22 & 22 \\
\hline & 2008 & 0.42 & -0.13 & 94 & 0.23 & -0.08 & 43 & 0.48 & -0.08 & 38 & 0.75 & -0.31 & 23 \\
\hline & 2009 & 0.42 & -0.04 & 93 & 0.26 & -0.05 & 42 & 0.54 & 0.07 & 41 & 0.66 & -0.23 & 20 \\
\hline \multirow{3}{*}{ US-Blk } & 2004 & 0.30 & -0.16 & 93 & 0.20 & 0.01 & 43 & 0.35 & -0.20 & 26 & 0.47 & -0.47 & 24 \\
\hline & 2006 & 0.26 & -0.07 & 94 & 0.30 & -0.05 & 47 & 0.27 & -0.12 & 24 & 0.19 & -0.06 & 23 \\
\hline & 2008 & 0.35 & -0.02 & 92 & 0.40 & 0.03 & 51 & 0.47 & 0.04 & 21 & 0.28 & 0.17 & 20 \\
\hline \multirow{2}{*}{ US-AR1 } & 2010 & 0.13 & 0.01 & 94 & 0.06 & 0.03 & 29 & 0.11 & -0.07 & 28 & 0.20 & 0.05 & 37 \\
\hline & 2011 & 0.21 & -0.18 & 93 & 0.04 & 0.01 & 25 & 0.21 & -0.17 & 22 & 0.34 & -0.34 & 46 \\
\hline \multirow{2}{*}{ US-KUT } & 2006 & 0.25 & 0.01 & 93 & 0.16 & 0.13 & 24 & 0.37 & -0.08 & 23 & 0.27 & -0.05 & 36 \\
\hline & 2007 & 0.23 & -0.15 & 92 & 0.10 & 0.01 & 31 & 0.31 & -0.20 & 25 & 0.30 & -0.23 & 36 \\
\hline CN-DNT-rice & 2016 & 0.40 & 0.19 & 28 & - & - & - & - & - & & - & - & - \\
\hline CN-DNT-wheat & $2014-15$ & 0.46 & -0.06 & 42 & - & - & - & - & - & & - & - & - \\
\hline PH-IRI & 2013 & 0.53 & -0.31 & 13 & - & - & - & - & - & & - & - & - \\
\hline
\end{tabular}

Table D2: As Table D1, but albedo (Eq. 6, Table 4) during snow-free periods (May-October; but the entire period for crops).

\begin{tabular}{|c|c|c|c|c|}
\hline site & year & MAE & MBE & $\mathbf{N}$ \\
\hline \multirow{3}{*}{ US-MMS } & 2010 & 0.007 & -0.003 & 177 \\
\cline { 2 - 5 } & 2012 & 0.007 & 0.001 & 183 \\
\cline { 2 - 5 } & 2016 & 0.008 & -0.003 & 182 \\
\hline \multirow{3}{*}{ US-UMB } & 2010 & 0.009 & -0.001 & 182 \\
\cline { 2 - 5 } & 2014 & 0.012 & -0.010 & 182 \\
\cline { 2 - 5 } & 2016 & 0.010 & -0.003 & 183 \\
\hline US-Oho & 2011 & 0.009 & -0.003 & 183 \\
\hline
\end{tabular}




\begin{tabular}{|c|c|c|c|c|}
\hline & 2012 & 0.009 & -0.004 & 183 \\
\hline & 2013 & 0.015 & -0.012 & 183 \\
\hline \multirow{3}{*}{ CA-Obs } & 2003 & 0.005 & -0.000 & 183 \\
\hline & 2005 & 0.007 & -0.003 & 175 \\
\hline & 2006 & 0.005 & -0.000 & 171 \\
\hline \multirow{3}{*}{ CA-Qcu } & 2005 & 0.014 & -0.001 & 180 \\
\hline & 2008 & 0.020 & -0.012 & 180 \\
\hline & 2009 & 0.023 & -0.019 & 183 \\
\hline \multirow{3}{*}{ US-Blk } & 2004 & 0.004 & -0.002 & 160 \\
\hline & 2006 & 0.008 & -0.005 & 176 \\
\hline & 2008 & 0.011 & -0.004 & 182 \\
\hline \multirow{2}{*}{ US-AR1 } & 2010 & 0.022 & 0.016 & 183 \\
\hline & 2011 & 0.025 & 0.025 & 183 \\
\hline \multirow{2}{*}{ US-KUT } & 2006 & 0.017 & 0.001 & 145 \\
\hline & 2007 & 0.017 & 0.004 & 148 \\
\hline $\begin{array}{l}\mathrm{CN}-\mathrm{DNT}- \\
\text { rice }\end{array}$ & 2016 & 0.016 & -0.001 & 123 \\
\hline $\begin{array}{c}\text { CN-DNT- } \\
\text { wheat }\end{array}$ & $\begin{array}{c}2014- \\
15\end{array}$ & 0.013 & 0.002 & 174 \\
\hline $\mathrm{PH}-\mathrm{IRI}$ & 2013 & 0.017 & 0.013 & 113 \\
\hline
\end{tabular}

572

573 Table D3: As Table D1, but for QE (Eq. 8 with Table 5 parameters). Units: $W m^{-2}$

\begin{tabular}{|c|c|c|c|c|c|c|c|c|c|c|c|c|c|}
\hline \multicolumn{2}{c|}{} & \multicolumn{3}{c|}{ Leaf-off } & \multicolumn{3}{c|}{ Leaf-trans } & \multicolumn{3}{c|}{ Leaf-on } & \multicolumn{4}{c|}{ All } \\
\hline site & year & MAE & MBE & N & MAE & MBE & N & MAE & MBE & N & MAE & MBE & N \\
\hline US-MMS & 2016 & 12.1 & -4.8 & 1330 & 42.2 & 20.7 & 3028 & 58.5 & 40.4 & 1057 & 37.8 & 18.1 & 5415 \\
\hline US-UMB & 2014 & 7.5 & -1.1 & 3410 & 28.2 & 9.1 & 2347 & 38.1 & 11.9 & 1288 & 19.9 & 4.6 & 7045 \\
\hline US-Oho & 2011 & 12.8 & -5.0 & 2255 & 26.4 & 3.7 & 2198 & 40.6 & -5.2 & 1588 & 25.0 & -1.9 & 6041 \\
\hline CA-Obs & 2006 & 8.3 & -2.3 & 2352 & 18.3 & 1.0 & 1844 & 42.4 & 32.7 & 1544 & 20.6 & 8.1 & 5740 \\
\hline CA-Qcu & 2005 & 6.1 & -4.9 & 2134 & 25.0 & -8.0 & 2007 & 47.0 & 21.9 & 1462 & 23.4 & 0.9 & 5603 \\
\hline US-BIk & 2006 & 19.3 & -16.5 & 3867 & 36.2 & -12.9 & 1907 & 43.3 & 8.8 & 1938 & 29.5 & -9.3 & 7709 \\
\hline US-AR1 & 2010 & 18.1 & -15.2 & 2338 & 48.1 & 8.1 & 2323 & 58.2 & 19.1 & 3291 & 43.5 & 5.8 & 7952 \\
\hline US-KUT & 2007 & 9.6 & -7.9 & 2059 & 24.7 & -18.2 & 1899 & 37.8 & 17.8 & 2338 & 24.6 & -1.5 & 6296 \\
\hline & & \multicolumn{3}{|c|}{ Vegetative } & \multicolumn{3}{|c|}{ Reproductive } & \multicolumn{3}{|c|}{ Ripening } & & & \\
\hline CN-DNT-rice & 2016 & 42.6 & 19.8 & 610 & 26.1 & -14.5 & 605 & 38.4 & 10.5 & 1095 & 36.3 & 6.4 & 2310 \\
\hline CN-DNT-wheat & 2014 & 19.6 & 10.4 & 1153 & 30.7 & -4.0 & 752 & 25.4 & 9.2 & 899 & 24.5 & 6.2 & 2804 \\
\hline PH-IRI-rice & 2013 & - & - & - & - & - & - & - & - & - & 44.5 & 28.3 & 1834 \\
\hline CN-DNT-soil & 2016 & - & - & - & - & - & - & - & - & - & 36.7 & -10.4 & 355 \\
\hline PH-IRI-soil & 2013 & - & - & - & - & - & - & - & - & - & 24.3 & -1.5 & 840 \\
\hline JP-SWL & - & - & - & - & - & - & - & - & - & - & 36.7 & 10.3 & 1229 \\
\hline
\end{tabular}

574

\section{Appendix E: $Q_{E}$ simulated with London and Swindon parameters}

576 To demonstrate the necessity and benefit of using appropriate parameters to estimate $Q_{E}$ in

577 SUEWS, we compare $Q_{E}$ simulated at DBF, ENF and GRA pervious sites using Ward et al.'s 
https://doi.org/10.5194/gmd-2020-148

Preprint. Discussion started: 17 July 2020

(c) Author(s) 2020. CC BY 4.0 License.

(c) (i)

578 (2016) $g_{\max }$ and $G_{2}-G_{6}$ parameters (derived for London and Swindon) (Fig. E1) to those derived

579 here (Table 5). In all cases the performance is improved using pervious area surface

580 parameters (e.g. $L A l$, albedo, surface conductance) than using the suburban/urban parameters

581 (assuming $\mathrm{f}_{\mathrm{i}}=1$ of the pervious area) (Fig. E2).
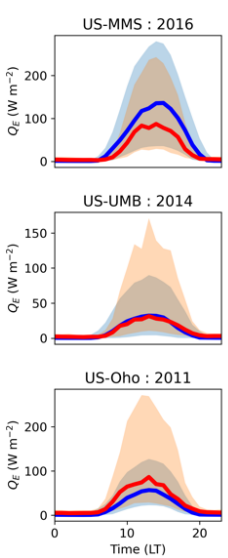

DBF

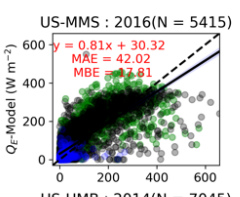

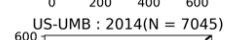
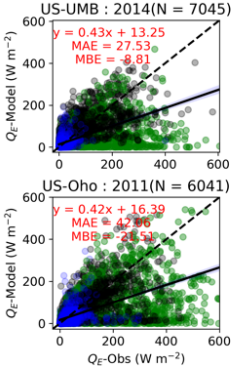
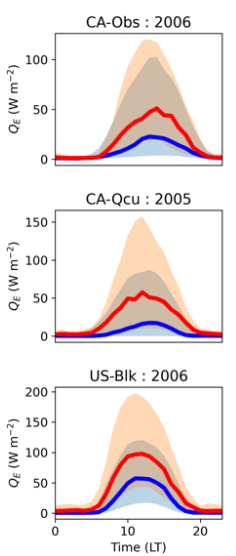

ENF

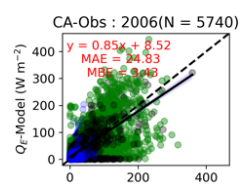

CA-QCu $: 2005$ ( $\mathrm{N}=5000$

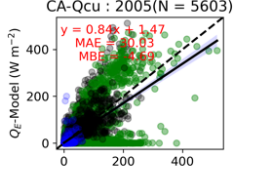

US-Blk : $2006(\mathrm{~N}=7706)$

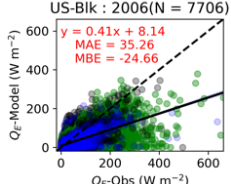

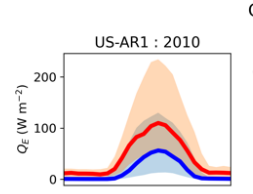

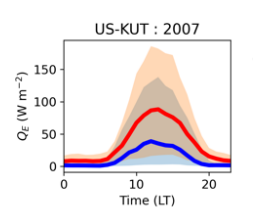

- leaf-off

- leaf-on

(Ripening-crop)
leaf-trans

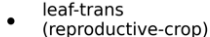

- Entire period
GRA

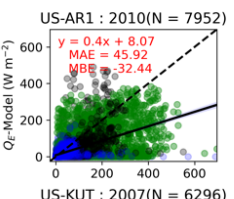

US-KUT : $2007(\mathrm{~N}=6296)$

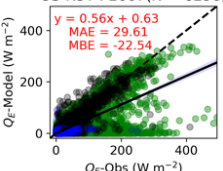

$200 \quad 400$
$Q_{E}=0 b s\left(\mathrm{~W} \mathrm{~m}^{-2}\right)$

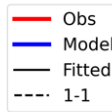

583 Figure E1: As Fig. 15, but using the parameters from Table A1 in Ward et al. (2016).

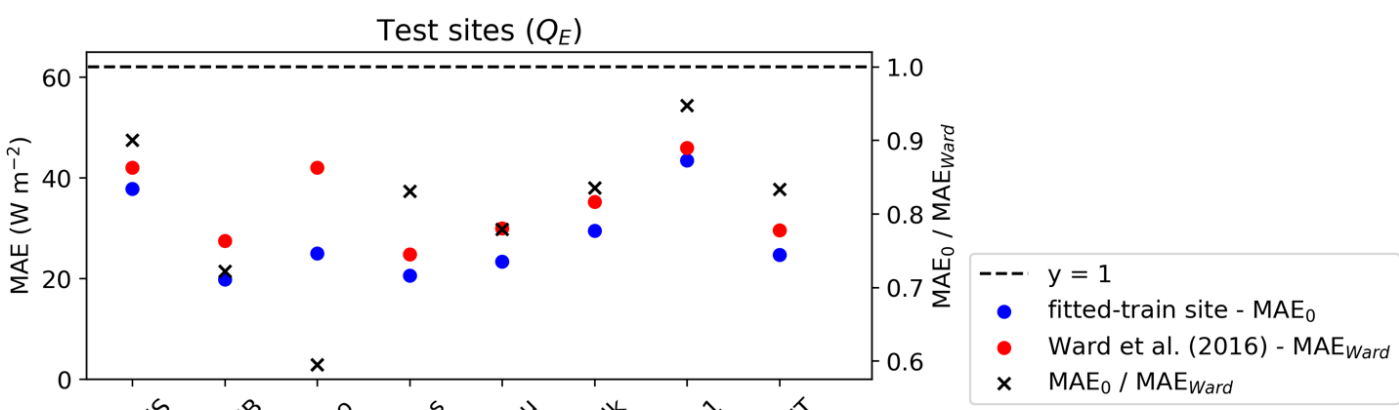

Figure E2: MAE for QE (Eq. 5) calculated with site-specific surface conductance parameters for sites

(Table 3) (i.e. Table 5, MAE ) and with the Ward et al. (2016) parameters (their Table A1) 

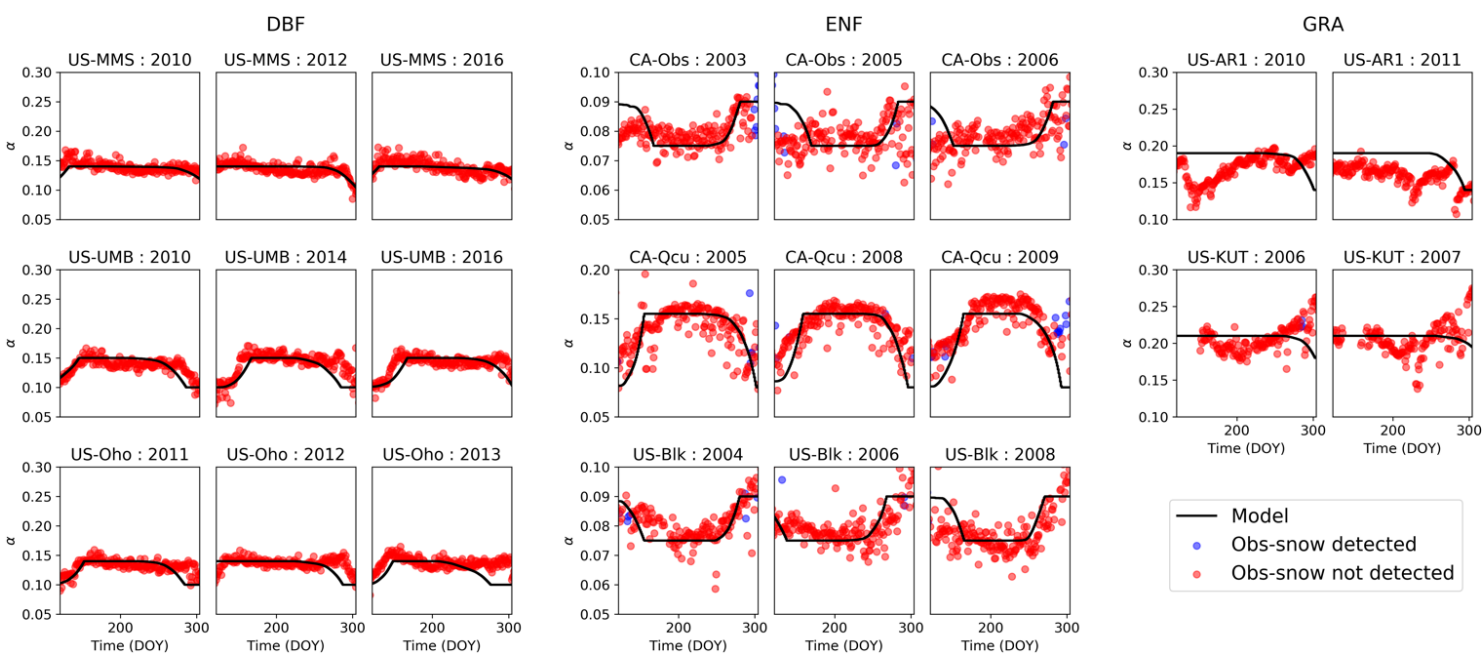

Figure F1: As Fig. 10, but only for May-October period.

\section{Code and data availability}

All source codes (Jupyter notebooks and Python scripts), input and output data are archived on Zenodo (https://doi.org/10.5281/zenodo.3831233, Omidvar et al., 2020)

\section{Author contribution}

$\mathrm{HO}$, TS and SG contributed to data preparation, model development, running simulations and writing the paper. All other authors $(\mathrm{DB}, \mathrm{AB}, \mathrm{JC}, \mathrm{ZD}, \mathrm{HI}$, and JM) provided data, interpreted the results, and reviewed the manuscript.

\section{Competing interest}

The authors declare that they have no conflict of interest.

\section{Acknowledgments}

This work is funded by NERC-COSMA project (NE/S005889/1), Newton Fund Met Office CSSPChina (SG), NERC Independent Research Fellowship (NE/P018637/1), National Natural Science Foundation of China (41875013; Zhiqiu Gao and Zexia Duan). We thank Pls for providing the data: Kim Novick and Rich Phillips (US-MMS); Christopher Gough, Gil Bohrer and Peter Curtis (US-UMB); Hank A. Margolis (CA-Qcu); Tilden Meyers (US-Blk); James Bradford, Margaret Torn (US-AR1); and Maricar Alberto, Caesar Arloo Centeno, Reiner Wassmann (PHIRI) 


\section{References}

610 Alberto, M. C. R., Wassmann, R., Hirano, T., Miyata, A., Kumar, A., Padre, A. and Amante, M.:

$611 \mathrm{CO}$ /heat fluxes in rice fields: Comparative assessment of flooded and non-flooded fields in the

612 Philippines, Agric. For. Meteorol., 149(10), 1737-1750, doi:10.1016/j.agrformet.2009.06.003,

6132009.

614 Alemu, W. and Henebry, G.: Characterizing Cropland Phenology in Major Grain Production

615 Areas of Russia, Ukraine, and Kazakhstan by the Synergistic Use of Passive Microwave and

616 Visible to Near Infrared Data, Remote Sens., 8(12), 1016, doi:10.3390/rs8121016, 2016.

617 Ao, X., Grimmond, C. S. B., Ward, H. C., Gabey, A. M., Tan, J., Yang, X.-Q., Liu, D., Zhi, X.,

618 Liu, H. and Zhang, N.: Evaluation of the Surface Urban Energy and Water Balance Scheme

619 (SUEWS) at a Dense Urban Site in Shanghai: Sensitivity to Anthropogenic Heat and Irrigation,

620 J. Hydrometeorol., 19(12), 1983-2005, doi:10.1175/JHM-D-18-0057.1, 2018.

621 AsiaFlux: AsiaFlux, [online] Available from: www.asiaflux.net (Accessed 22 January 2020),

6222003.

623 Baldocchi, D., Falge, E., Gu, L., Olson, R., Hollinger, D., Running, S., Anthoni, P., Bernhofer, C.,

624 Davis, K., Evans, R., Fuentes, J., Goldstein, A., Katul, G., Law, B., Lee, X., Malhi, Y., Meyers,

625 T., Munger, W., Oechel, W., Paw, U. K. T., Pilegaard, K., Schmid, H. P., Valentini, R., Verma,

626 S., Vesala, T., Wilson, K. and Wofsy, S.: FLUXNET: A New Tool to Study the Temporal and

627 Spatial Variability of Ecosystem-Scale Carbon Dioxide, Water Vapor, and Energy Flux

628 Densities, Bull. Am. Meteorol. Soc., 82(11), 2415-2434, doi:10.1175/1520-

629 0477(2001)082<2415:FANTTS>2.3.CO;2, 2001.

630 Basemap: Basemap Toolkit documentation, [online] Available from:

631 https://matplotlib.org/basemap/ (Accessed 13 February 2020), 2012.

632 Bauerle, W. L., Oren, R., Way, D. A., Qian, S. S., Stoy, P. C., Thornton, P. E., Bowden, J. D., 633 Hoffman, F. M. and Reynolds, R. F.: Photoperiodic regulation of the seasonal pattern of

634 photosynthetic capacity and the implications for carbon cycling, Proc. Natl. Acad. Sci. U. S. A., 635 109(22), 8612-8617, doi:10.1073/pnas.1119131109, 2012.

636 Bergeron, O., Margolis, H. A., Black, T. A., Coursolle, C., Dunn, A. L., Barr, A. G. and Wofsy, S. 637 C.: Comparison of carbon dioxide fluxes over three boreal black spruce forests in Canada, Glob.

638 Chang. Biol., 13(1), 89-107, doi:10.1111/j.1365-2486.2006.01281.x, 2007. 
639 Billesbach, D., Bradford, J. and Torn, M.: AmeriFlux US-AR1 ARM USDA UNL OSU Woodward

640 Switchgrass 1, AmeriFlux Netw., doi:10.17190/AMF/1246137, 2009.

641 Black, T. A.: AmeriFlux CA-Obs Saskatchewan - Western Boreal, Mature Black Spruce, , 642 doi:10.17190/AMF/1375198, 2017.

643 Bobée, C., Ottlé, C., Maignan, F., De Noblet-Ducoudré, N., Maugis, P., Lézine, A. M. and

644 Ndiaye, M.: Analysis of vegetation seasonality in Sahelian environments using MODIS LAI, in

645 association with land cover and rainfall, J. Arid Environ., 84, 38-50,

646 doi:10.1016/j.jaridenv.2012.03.005, 2012.

647 Brutsaert, W.: Evaporation into the Atmosphere, Springer Netherlands, Dordrecht., 1982.

648 Campbell, G. S. and Norman, J. M.: An Introduction to Environmental Biophysics, in An

649 Introduction to Environmental Biophysics, pp. 1-13, Springer New York, New York, NY., 1998.

650 Chen, J.: AmeriFlux US-Oho Oak Openings, , doi:10.17190/amf/1246089, 2016.

651 Curtis, P. and Gough, C.: AmeriFlux US-UMB Univ. of Mich. Biological Station, , 652 doi:10.17190/AMF/1246107, 2016.

653 Curtis, P. S., Hanson, P. J., Bolstad, P., Barford, C., Randolph, J. C., Schmid, H. P. and Wilson, 654 K. B.: Biometric and eddy-covariance based estimates of annual carbon storage in five eastern 655 North American deciduous forests, Agric. For. Meteorol., 113(1-4), 3-19, doi:10.1016/S0168656 1923(02)00099-0, 2002.

657 Doll, D., Ching, J. K. S. and Kaneshiro, J.: Parameterization of subsurface heating for soil and 658 concrete using net radiation data, Boundary-Layer Meteorol., 32(4), 351-372,

659 doi:10.1007/BF00122000, 1985.

660 Duan, Z., Grimmond, S., Zhiqui, G., Sun, T., Liu, C. and Li, Y.: Radiation, energy, CO2 fluxes 661 and energy balance closure over rice-wheat rotation: diurnal, seasonal and interannual (2014662 2017) variations (under review), Agric. For. Meteorol., 2020.

663 Ek, M. B., Mitchell, K. E., Lin, Y., Rogers, E., Grunmann, P., Koren, V., Gayno, G. and Tarpley, 664 J. D.: Implementation of Noah land surface model advances in the National Centers for 665 Environmental Prediction operational mesoscale Eta model, J. Geophys. Res. Atmos., 666 108(D22), 2002JD003296, doi:10.1029/2002JD003296, 2003.

667 Garratt, J.: Review: the atmospheric boundary layer, Earth-Science Rev., 37(1-2), 89-134, 

doi:10.1016/0012-8252(94)90026-4, 1994.

669 Gascoin, S., Ducharne, A., Ribstein, P., Perroy, E. and Wagnon, P.: Sensitivity of bare soil 670 albedo to surface soil moisture on the moraine of the Zongo glacier (Bolivia), Geophys. Res. 671 Lett., 36(2), n/a-n/a, doi:10.1029/2008GL036377, 2009.

672 Gill, A. L., Gallinat, A. S., Sanders-DeMott, R., Rigden, A. J., Short Gianotti, D. J., Mantooth, J. 673 A. and Templer, P. H.: Changes in autumn senescence in northern hemisphere deciduous 674 trees: a meta-analysis of autumn phenology studies, Ann. Bot., 116(6), 875-888, 675 doi:10.1093/aob/mcv055, 2015.

676 Grimmond, C. S. B.: The suburban energy balance: Methodological considerations and results 677 for a mid-latitude west coast city under winter and spring conditions, Int. J. Climatol., 12(5), 678 481-497, doi:10.1002/joc.3370120506, 1992.

679 Grimmond, C. S. B. and Oke, T. R.: An evapotranspiration-interception model for urban areas, 680 Water Resour. Res., 27(7), 1739-1755, doi:10.1029/91WR00557, 1991.

681 Grimmond, C. S. B. and Oke, T. R.: Aerodynamic Properties of Urban Areas Derived from 682 Analysis of Surface Form, J. Appl. Meteorol., 38(9), 1262-1292, doi:10.1175/1520683 0450(1999)038<1262:APOUAD>2.0.CO;2, 1999.

684 Grimmond, C. S. B., Oke, T. R. and Steyn, D. G.: Urban Water Balance: 1. A Model for Daily 685 Totals, Water Resour. Res., 22(10), 1397-1403, doi:10.1029/WR022i010p01397, 1986.

686 Grimmond, C. S. B., Cleugh, H. A. and Oke, T. R.: An objective urban heat storage model and 687 its comparison with other schemes, Atmos. Environ. Part B. Urban Atmos., 25(3), 311-326, 688 doi:10.1016/0957-1272(91)90003-W, 1991.

689 Grimmond, C. S. B., King, T. S., Roth, M. and Oke, T. R.: Aerodynamic roughness of urban 690 areas derived from wind observations, Boundary-Layer Meteorol., 89(1), 1-24, 691 doi:10.1023/A:1001525622213, 1998.

692 Grimmond, C. S. B., Blackett, M., Best, M. J., Barlow, J., Baik, J. J., Belcher, S. E., 693 Bohnenstengel, S. I., Calmet, I., Chen, F., Dandou, A., Fortuniak, K., Gouvea, M. L., Hamdi, R., 694 Hendry, M., Kawai, T., Kawamoto, Y., Kondo, H., Krayenhoff, E. S., Lee, S. H., Loridan, T., 695 Martilli, A., Masson, V., Miao, S., Oleson, K., Pigeon, G., Porson, A., Ryu, Y. H., Salamanca, F., 696 Shashua-Bar, L., Steeneveld, G. J., Tombrou, M., Voogt, J., Young, D. and Zhang, N.: The 697 international urban energy balance models comparison project: First results from phase 1, J. 
Appl. Meteorol. Climatol., 49(6), 1268-1292, doi:10.1175/2010JAMC2354.1, 2010. 2020), 2015. scheme over a tropical suburban neighborhood, Theor. Appl. Climatol., 133(3-4), 867-886, doi:10.1007/s00704-017-2221-7, 2018.

Högström, U.: Non-dimensional wind and temperature profiles in the atmospheric surface layer: A re-evaluation, Boundary-Layer Meteorol., 42(1-2), 55-78, doi:10.1007/BF00119875, 1988. Iwata, H., Hirata, R., Takahashi, Y., Miyabara, Y., Itoh, M. and lizuka, K.: Partitioning Eddy-

707 Covariance Methane Fluxes from a Shallow Lake into Diffusive and Ebullitive Fluxes, BoundaryLayer Meteorol., 169(3), 413-428, doi:10.1007/s10546-018-0383-1, 2018. Scheme (SUEWS): Evaluation in Los Angeles and Vancouver, J. Hydrol., 411(3-4), 219-237, doi:10.1016/j.jhydrol.2011.10.001, 2011.

712 Järvi, L., Grimmond, C. S. B., Taka, M., Nordbo, A., Setälä, H. and Strachan, I. B.: Development 713 of the Surface Urban Energy and Water Balance Scheme (SUEWS) for cold climate cities,

714 Geosci. Model Dev., 7(4), 1691-1711, doi:10.5194/gmd-7-1691-2014, 2014.

715 Järvi, L., Havu, M., Ward, H. C., Bellucco, V., McFadden, J. P., Toivonen, T., Heikinheimo, V., 716 Kolari, P., Riikonen, A. and Grimmond, C. S. B.: Spatial Modeling of Local-Scale Biogenic and 717 Anthropogenic Carbon Dioxide Emissions in Helsinki, J. Geophys. Res. Atmos., 2018JD029576, 718 doi:10.1029/2018JD029576, 2019.

719 Karsisto, P., Fortelius, C., Demuzere, M., Grimmond, C. S. B., Oleson, K. W., Kouznetsov, R., 720 Masson, V. and Järvi, L.: Seasonal surface urban energy balance and wintertime stability 721 simulated using three land-surface models in the high-latitude city Helsinki, Q. J. R. Meteorol. 722 Soc., 142(694), 401-417, doi:10.1002/qj.2659, 2016.

723 Kawai, T., Ridwan, M. K. and Kanda, M.: Evaluation of the simple urban energy balance model 724 using selected data from 1-yr flux observations at two cities, J. Appl. Meteorol. Climatol., 48(4), 725 693-715, doi:10.1175/2008JAMC1891.1, 2009.

726 Kent, C. W., Grimmond, S. and Gatey, D.: Aerodynamic roughness parameters in cities: 
Inclusion of vegetation, J. Wind Eng. Ind. Aerodyn., 169, 168-176, doi:10.1016/j.jweia.2017.07.016, 2017a.

729 Kent, C. W., Lee, K., Ward, H. C., Hong, J.-W., Hong, J., Gatey, D. and Grimmond, S.:

730 Aerodynamic roughness variation with vegetation: analysis in a suburban neighbourhood and a

731 city park, Urban Ecosyst., doi:10.1007/s11252-017-0710-1, 2017b.

732 Keyser, T. L., Lentile, L. B., Smith, F. W. and Shepperd, W. D.: Changes in Forest Structure

733 After a Large, Mixed-Severity Wildfire in Ponderosa Pine Forests of the Black Hills, South

734 Dakota, USA., 2008.

735 Kokkonen, T. V., Grimmond, C. S. B., Räty, O., Ward, H. C., Christen, A., Oke, T. R., Kotthaus,

736 S. and Järvi, L.: Sensitivity of Surface Urban Energy and Water Balance Scheme (SUEWS) to

737 downscaling of reanalysis forcing data, Urban Clim., 23, 36-52,

738 doi:10.1016/j.uclim.2017.05.001, 2018.

739 Kowalczyk, E. A., Wang, Y. P. and Law, R. M.: The CSIRO Atmosphere Biosphere Land

740 Exchange (CABLE) model for use in climate models and as an offline model, CSIRO Mar.

741 Atmos. Res. Pap., 13(November 2015), 1-42, doi:https://doi.org/10.4225/08/58615c6a9a51d,

7422006.

743 Krinner, G., Viovy, N., de Noblet-Ducoudré, N., Ogée, J., Polcher, J., Friedlingstein, P., Ciais,

744 P., Sitch, S. and Prentice, I. C.: A dynamic global vegetation model for studies of the coupled

745 atmosphere-biosphere system, Global Biogeochem. Cycles, 19(1), doi:10.1029/2003GB002199,

7462005.

747 Kusaka, H., Kondo, H., Kikegawa, Y. and Kimura, F.: A Simple Single-Layer Urban Canopy

748 Model For Atmospheric Models: Comparison With Multi-Layer And Slab Models, Boundary-

749 Layer Meteorol., 101(3), 329-358, doi:10.1023/A:1019207923078, 2001.

750 Levis, S., Bonan, G. B., Vertenstein, M. and Oleson, K. W.: Technical Documentation and

751 User's Guide to the Community Land Model's Dynamic Global Vegetation Model, ,

752 doi:10.5065/D6P26W36, 2004.

753 Liu, Y., Xie, R., Hou, P., Li, S., Zhang, H., Ming, B., Long, H. and Liang, S.: Phenological

754 responses of maize to changes in environment when grown at different latitudes in China, $F$.

755 Crop. Res., 144, 192-199, doi:10.1016/j.fcr.2013.01.003, 2013.

756 Loridan, T., Grimmond, C. S. B., Offerle, B. D., Young, D. T., Smith, T. E. L., Järvi, L. and 
757 Lindberg, F.: Local-Scale Urban Meteorological Parameterization Scheme (LUMPS): Longwave

758 Radiation Parameterization and Seasonality-Related Developments, J. Appl. Meteorol.

759 Climatol., 50(1), 185-202, doi:10.1175/2010JAMC2474.1, 2011.

760 Margolis, H. A.: AmeriFlux CA-Qcu Quebec - Eastern Boreal, Black Spruce/Jack Pine Cutover, , 761 doi:10.17190/AMF/1246828, 2001.

762 Martilli, A., Clappier, A. and Rotach, M. W.: An Urban Surface Exchange Parameterisation for

763 Mesoscale Models, Boundary-Layer Meteorol., 104(2), 261-304,

764 doi:10.1023/A:1016099921195, 2002.

765 Masson, $\mathrm{V} .:$ A physically-based scheme for the urban energy budget in atmospheric models,

766 Boundary-Layer Meteorol., 94(3), 357-397, doi:10.1023/A:1002463829265, 2000.

767 McCaughey, J. H.: Energy balance storage terms in a mature mixed forest at Petawawa,

768 Ontario - A case study, Boundary-Layer Meteorol., 31(1), 89-101, doi:10.1007/BF00120036,

7691985.

770 McFadden J. P.: AmeriFlux US-KUT KUOM Turfgrass Field, , doi:10.17190/AMF/1246145,

7712009.

772 Meyers and Tilden: AmeriFlux US-Blk Black Hills, , doi:10.17190/AMF/1246031, 2016.

773 Moene, A. F. and van Dam, J. C.: Transport in the Atmosphere-Vegetation-Soil Continuum, 774 Cambridge University Press., 2013.

775 Monin, A. S. and Obukhov, A. M.: Basic laws of turbulent mixing in the surface layer of the

776 atmosphere, Contrib. Geophys. Inst. Acad. Sci. USSR, 24(151), 163-187, 1954.

777 Monteith, J. L.: Evaporation and environment., Symp. Soc. Exp. Biol., 19(19), 205-34 [online]

778 Available from: http://www.ncbi.nlm.nih.gov/pubmed/5321565 (Accessed 21 October 2019),

7791965.

780 Myneni, R., Knyazikhin, Y. and Park, T.: MCD15A3H MODIS/Terra+Aqua Leaf Area

781 Index/FPAR 4-day L4 Global 500m SIN Grid V006. NASA EOSDIS Land Processes DAAC, 7822015.

783 Nations, U.: 2018 revision of world urbanization prospects, 2018.

784 Nishihama, M., Wolfe, R., Solomon, D., Patt, F., Blanchette, J., Fleig, A. and Masuoka, E.: 
785 MODIS Level 1A Earth Location: Algorithm Theoretical Basis Document By the MODIS Science

786 Data Support Team, Greenbelt, Md., 1997.

787 Noormets, A., McNulty, S. G., DeForest, J. L., Sun, G., Li, Q. and Chen, J.: Drought during

788 canopy development has lasting effect on annual carbon balance in a deciduous temperate

789 forest, New Phytol., 179(3), 818-828, doi:10.1111/j.1469-8137.2008.02501.x, 2008.

790 Nunez, M., Davies, J. A. and Robinson, P. J.: Surface albedo at a tower site in Lake Ontario,

791 Boundary-Layer Meteorol., 3(1), 77-86, doi:10.1007/BF00769108, 1972.

792 Offerle, B., Grimmond, C. S. B. and Oke, T. R.: Parameterization of Net All-Wave Radiation for

793 Urban Areas, J. Appl. Meteorol., 42(8), 1157-1173, doi:10.1175/1520-

794 0450(2003)042<1157:PONARF>2.0.CO;2, 2003.

795 Omidvar, H., Sun, T. and Grimmond, C. S. B.: Assets for SUEWS Parameters calculation, , 796 doi:10.5281/zenodo.3831233, 2020.

797 Penman, H. L.: Natural evaporation from open water, hare soil and grass, Proc. R. Soc. Lond.

798 A. Math. Phys. Sci., 193(1032), 120-145, doi:10.1098/rspa.1948.0037, 1948.

799 Peters, E. B., Hiller, R. V. and McFadden, J. P.: Seasonal contributions of vegetation types to

800 suburban evapotranspiration, J. Geophys. Res. Biogeosciences, 116(1), G01003,

801 doi:10.1029/2010JG001463, 2011.

802 Philip Bloomington, R. and Novick Bloomington, K.: AmeriFlux US-MMS Morgan Monroe State

803 Forest, , doi:10.17190/AMF/1246080, 2016.

804 Porter, C. L.: An Analysis of Variation Between Upland and Lowland Switchgrass, Panicum

805 Virgatum L., in Central Oklahoma, Ecology, 47(6), 980-992, doi:10.2307/1935646, 1966.

806 Schmid, H. P., Grimmond, C. S. B., Cropley, F., Offerle, B. and Su, H. B.: Measurements of

$807 \mathrm{CO} 2$ and energy fluxes over a mixed hardwood forest in the mid-western United States, Agric.

808 For. Meteorol., 103(4), 357-374, doi:10.1016/S0168-1923(00)00140-4, 2000.

809 Shuttleworth, W. J.: A simplified one-dimensional theoretical description of the vegetation-

810 atmosphere interaction, Boundary-Layer Meteorol., 14(1), 3-27, doi:10.1007/BF00123986,

8111978.

812 Shuttleworth, W. J.: Evaporation models in the global water budget., Var. Glob. water Budg., 813 147-171, doi:10.1007/978-94-009-6954-4_11, 1983. 
814 Spronken-Smith, R. A., Oke, T. R. and Lowry, W. P.: Advection and the surface energy balance

815 across an irrigated urban park, Int. J. Climatol., 20(9), 1033-1047, doi:10.1002/1097-

816 0088(200007)20:9<1033::AID-JOC508>3.0.CO;2-U, 2000.

817 Sun, T. and Grimmond, S.: A Python-enhanced urban land surface model SuPy (SUEWS in

818 Python, v2019.2): development, deployment and demonstration, Geosci. Model Dev, 12, 2781-

819 2795, doi:10.5194/gmd-12-2781-2019, 2019.

820 Sun, T., Järvi, L., Omidvar, H., Theeuwes, N., Lindberg, F., Li, Z. and Grimmond, S.: Urban-

821 Meteorology-Reading/SUEWS: 2020a Release, , doi:10.5281/zenodo.3828525, 2020.

822 Van Ulden, A. P. and Holtslag, A. A. M.: Estimation of atmospheric boundary layer parameters

823 for diffusion applications., J. Clim. Appl. Meteorol., 24(11), 1196-1207, doi:10.1175/1520-

824 0450(1985)024<1196:EOABLP>2.0.CO;2, 1985.

825 Ward, H. C., Kotthaus, S., Järvi, L. and Grimmond, C. S. B.: Surface Urban Energy and Water 826 Balance Scheme (SUEWS): Development and evaluation at two UK sites, Urban Clim., 18, 1827 32, doi:10.1016/j.uclim.2016.05.001, 2016.

828 Zhou, A., Qu, B.-Y., Li, H., Zhao, S.-Z., Suganthan, P. N. and Zhang, Q.: Multiobjective 829 evolutionary algorithms: A survey of the state of the art, Swarm Evol. Comput., 1(1), 32-49, 830 doi:10.1016/j.swevo.2011.03.001, 2011. 